\title{
Divergent effects of Wolbachia on host temperature preference
}

Michael T.J. Hague ${ }^{1 *}$, Chelsey N. Caldwell ${ }^{1}$, and Brandon S. Cooper ${ }^{1}$

${ }^{1}$ Division of Biological Sciences

University of Montana

32 Campus Dr.

Missoula, MT 59812

*Corresponding Author

Michael T.J. Hague

Division of Biological Sciences, University of Montana

32 Campus Dr. HS 104, Missoula, MT 59812

(406) 243-5122

michael.hague@mso.umt.edu 


\section{ABSTRACT}

$2 \quad$ Heritable symbionts can modify a range of ecologically important host traits, including

3 behavior. About half of all insect species are infected with maternally transmitted Wolbachia, a

4 bacterial endosymbiont known to alter host reproduction, nutrient acquisition, and virus

5 susceptibility. Here, we broadly test the hypothesis that Wolbachia modify host behavior by

6 assessing the effects of eight different Wolbachia strains on the temperature preference of six

7 Drosophila melanogaster-subgroup species. Four of the seven host genotypes infected with A-

8 group Wolbachia strains (wRi in D. simulans, $w$ Ha in D. simulans, $w$ Sh in D. sechellia, and $w$ Tei

9 in D. teissieri) prefer significantly cooler temperatures relative to uninfected genotypes.

10 Contrastingly, when infected with divergent B-group wMau, D. mauritiana prefer a warmer

11 temperature. For most strains, changes to host temperature preference do not alter Wolbachia

12 titer. However, males infected with $w$ Sh and $w$ Tei experience an increase in titer when shifted to

13 a cooler temperature for 24 hours, suggesting that Wolbachia-induced changes to host behavior

14 may promote bacterial replication and influence Wolbachia transmission rates. Modifications to

15 host temperature preference likely influence host thermoregulation, and understanding the fitness

16 consequences of these effects is crucial for predicting evolutionary outcomes of host-symbiont

17 interactions, including how Wolbachia spread to become common.

19 KEYWORDS: Drosophila, host-microbe interaction, symbiosis, thermal adaptation,

20 thermoregulation, $w \mathrm{Mel}$ 


\section{INTRODUCTION}

Heritable symbionts have diverse ecological effects on their hosts. In insects, microbial symbionts influence host reproduction (e.g., cytoplasmic incompatibility; Hoffmann and Turelli 1997; Werren et al. 2008), acquisition of nutrients (Baumann 2005; Moran et al. 2008; Douglas 2009), tolerance of extreme temperatures (Brumin et al. 2011; Mueller et al. 2011), and susceptibility to viruses (Hedges et al. 2008; Teixeira et al. 2008). Much less is known about symbionts' effects on host behavior and their ecological consequences (Feldhaar 2011; Goodacre and Martin 2012; Bi and Wang 2019; Hosokawa and Fukatsu 2020). On the one hand, symbionts may induce behavioral changes that promote the spread of infection through host populations. Because symbiotic relationships can span a continuum from mutualism to parasitism, behavioral modifications that promote infection spread may not necessarily benefit hosts (Hentschel et al. 2000; Werren et al. 2008). Parasites, for example, can induce behaviors that are detrimental or lethal to hosts, such as altering host locomotor behavior to increase the probability of parasite transmission (Lefevre and Thomas 2008; Poulin 2010; van Houte et al. 2013; Heil 2016; Vale et al. 2018; Weinersmith 2019). On the other hand, infected hosts may modify their own behavior in ways that mitigate negative aspects of the infection (Hart 1988; Poulin 2010; De Roode and Lefèvre 2012; Curtis 2014), such as a "behavioral chill" thermoregulatory response in which hosts seek cool temperatures to increase their survival probability (Fedorka et al. 2016). These behavioral effects represent an important component of how symbionts impact host fitness, which ultimately dictates the evolutionary trajectory of host-symbiont interactions.

Maternally transmitted Wolbachia are the most common endosymbionts in nature, infecting the cells of about half of all insect species, as well as other arthropods (Werren et al. 2008; Zug and Hammerstein 2012; Weinert et al. 2015). Wolbachia and host phylogenies are often discordant (O’Neill et al. 1992; Raychoudhury et al. 2009; Gerth and Bleidorn 2017), and most Drosophila hosts have acquired Wolbachia via introgressive and/or horizontal transfer within only the last few thousand years (Conner et al. 2017; Turelli et al. 2018; Cooper et al.

47 2019). Maternal transmission occurs in the host germline, but Wolbachia also infect a variety of host somatic cells, including metabolic, digestive, and nervous system tissue (Dobson et al. 1999; Albertson et al. 2009; Pietri et al. 2016). The fitness consequences of Wolbachia in host

50 tissues ultimately determine infection spread, and initial spread from low frequencies requires 51 positive Wolbachia effects on host fitness (Caspari and Watson 1959; Hoffmann et al. 1990; 
52 Barton and Turelli 2011). Exactly how Wolbachia alter components of host fitness is poorly

53 understood (Ross et al. 2019b), even though theoretical and population-level analyses indicate

54 pervasive positive effects on host fitness (Hoffmann et al. 1990; Hoffmann and Turelli 1997;

55 Kriesner and Hoffmann 2018; Turelli et al. 2018; Meany et al. 2019; Hague et al. 2020).

Symbionts are known to influence host thermal tolerance (Russell and Moran 2006;

Dunbar et al. 2007; Mueller et al. 2011; Wernegreen 2012; Zhang et al. 2019), and two recent studies found that D. melanogaster lines infected with the $w \mathrm{MelCS}$ or $w \mathrm{Mel}$ Wolbachia strains tend to prefer cooler temperatures than uninfected genotypes (Arnold et al. 2019; Truitt et al. 2019). Modifications to host temperature preference $\left(T_{p}\right)$ have important implications for insects, because ectothermic performance and fitness explicitly depend on temperature (Angilletta et al. 2004; Martin and Huey 2008; Dillon et al. 2009; Garrity et al. 2010; Hoffmann and Sgro 2011; Condon et al. 2014; Rajpurohit and Schmidt 2016). Because Wolbachia infect most insects

64 (Werren et al. 2008; Zug and Hammerstein 2012; Weinert et al. 2015), it is crucial to understand how infections alter host thermoregulation. Few past analyses of insect behavioral thermoregulation have accounted for Wolbachia (Dillon et al. 2009; Hoffmann 2010; Rajpurohit and Schmidt 2016).

Differences in $T_{p}$ between infected and uninfected flies could arise from conflicting physiological requirements of Wolbachia and their hosts. Wolbachia titer in host bodies is sensitive to temperature fluctuations (López-Madrigal and Duarte 2019), such that exceedingly $\operatorname{cool}\left(<20^{\circ} \mathrm{C}\right)$ and warm $\left(>25^{\circ} \mathrm{C}\right)$ temperatures reduce titer and the efficiency of maternal Wolbachia transmission (Clancy and Hoffmann 1998; Ulrich et al. 2016; Ross et al. 2017, 2019a; Foo et al. 2019; López-Madrigal and Duarte 2019; Hague et al. 2020). Wolbachiainduced changes to $T_{p}$ could provide more favorable thermal conditions for bacteria replication in hosts. Alternatively, host-induced changes to $T_{p}$ could represent a host behavioral response that reduces Wolbachia titer to mitigate negative aspects of infection (e.g., behavioral chill). It is still unknown whether observed changes to $T_{p}$ increase or decrease Wolbachia titer (Arnold et al. 2019; Truitt et al. 2019). 
83 infected genotype ( $w$ Mau in D. mauritiana), which diverged from A-group strains 6 to 46

84 million years ago (Meany et al. 2019). We find that hosts infected with four of the A-group

85 Wolbachia strains ( $w \mathrm{Ri}, w \mathrm{Ha}, w \mathrm{Sh}$, and $w$ Tei) prefer a significantly cooler $T_{p}$ than uninfected

86 flies of the same host genotype. In contrast, D. mauritiana infected with B-group wMau have a

87 significantly warmer $T_{p}$. Notably, we find no evidence for $w \mathrm{MelCS}$ or $w \mathrm{Mel}$ effects on $T_{p}$ of $D$. melanogaster, which may be due to host effects. Shifting infected adults from an intermediate temperature towards their $T_{p}$ for 24 hours generally does not alter Wolbachia titer, but in a few instances, reductions in host $T_{p}$ seem to promote Wolbachia replication. Our results motivate future work on the causes and consequences of Wolbachia effects on $T_{p}$ and other host behaviors.

\section{METHODS}

$94 \quad$ Fly Lines

We broadly tested whether Wolbachia alter $T_{p}$ of their Drosophila host species. We evaluated eight different Wolbachia strains infecting six different species in the D. melanogaster subgroup (Supplemental Table S1). For two of these host species, we tested multiple Wolbachiainfected genotypes: $w$ MelCS- and $w$ Mel-infected D. melanogaster and $w \mathrm{Ri}$ - and $w \mathrm{Ha}$-infected D. simulans. With the exception of the wMelCS-D. melanogaster line (Canton S Berkeley), all our Wolbachia-infected genotypes were naturally sampled to form isofemale lines, such that single gravid females were collected from the field and placed individually in vials. $w$ MelCS is

102 only found at low frequency in global populations of D. melanogaster (Riegler et al. 2005;

103 Nunes et al. 2008; Richardson et al. 2012), because the strain has been largely replaced by a 104 recent sweep of $w \mathrm{Mel}$ in roughly the last 5,000 years (Riegler et al. 2005; Nunes et al. 2008;

105 Richardson et al. 2012; Cooper et al. 2019). wMelCS was originally identified in the common

106 laboratory strain Canton Special (Stern 1943; Stern and Schaeffer 1943; Riegler et al. 2005), and

107 a sub-strain (Canton S Berkeley) was kindly provided to us by Michael Turelli. All lines were 108 maintained on standard cornmeal media prior to experiments.

$109 \quad$ We generated Wolbachia-uninfected genotypes by treating each infected line with $0.03 \%$ 110 tetracycline for four generations. In the fourth generation, we used PCR to confirm flies were 111 cleared of Wolbachia. We amplified both the Wolbachia surface protein (wsp) and a second set 112 of primers for the arthropod-specific $28 S$ rDNA that served as a positive control (Cooper et al. 113 2017; Meany et al. 2019). We then reconstituted the gut microbiome of the tetracycline-cleared 
114 flies by rearing them on food where infected males of the same genotype had fed and defecated

115 for the prior 48 hours. Tetracycline-cleared flies were given at least three more generations

116 before we conducted experiments to avoid detrimental effects of the antibiotic treatment on

117 mitochondrial function (Ballard and Melvin 2007).

Host Temperature Preference Assays

We assayed $T_{p}$ of each genotype using a thermal gradient apparatus adapted from Matute et al. (2009) and Goda (2014). The rectangular thermal gradient comprised a 44 x 13 x $1 \mathrm{~cm}$ plate of aluminum with a removable Plexiglas lid (Supplemental Figure S1). The Plexiglas lid

124 thermal gradient. We created an air-tight seal between the aluminum plate and the Plexiglas lid 125 using double-sided tape and C-clamps. To keep flies on the temperature-controlled aluminum 126 plate and off the lid, the Plexiglas was coated with Fluon (BioQuip Products), a slick barrier that 127 prevents insects from obtaining a foothold (Dierick 2007; Dankert et al. 2009). An LED light 128 was placed above the apparatus to ensure light was evenly distributed across the entire thermal 129 gradient.

All $T_{p}$ assays were conducted in a cold storage room with a constant temperature of $5^{\circ} \mathrm{C}$.

131 A hot plate set to $90^{\circ} \mathrm{C}$ was placed under one end of the aluminum plate to create a thermal

132 gradient. All experiments began once the apparatus achieved thermal stability after

133 approximately 0.5 hours. The aluminum plate was subdivided into seven $10 \times 6 \mathrm{~cm}$ sections

134 (Supplemental Figure S1), and we recorded the temperature at the center of each section using a

135 thermocouple (Digi-Sense Traceable $\left.{ }^{\circledR}\right)$ prior to the start of each experiment. Temperature

136 decreased linearly along the gradient $\left(\mathrm{R}^{2}=0.92\right)$, ranging from a mean of $34^{\circ} \mathrm{C}$ at the warmest

137 end (section 1) to $17^{\circ} \mathrm{C}$ at the coldest end (section 7). Mean temperatures at the center point of

138 each section across all experiments are shown in Supplemental Figure S2 and Table S2.

139 The following protocol for our assay was adapted from previous experiments (Matute et

140 al. 2009; Goda et al. 2014; Rajpurohit and Schmidt 2016; Truitt et al. 2019). Trial runs revealed

141 that a sample size of 50-60 flies allowed flies to distribute across the gradient without

142 overcrowding in preferred temperature ranges, which is consistent with prior studies (Matute et

143 al. 2009; Truitt et al. 2019). Flies were reared in a $25^{\circ} \mathrm{C}$ incubator under a 12L:12D light cycle

144 (Pericival Model I-36LL) on a standard food diet. For each genotype, we collected virgin flies as 
145 a batch and separated them into four treatment groups: uninfected females, infected females,

146 uninfected males, and infected males. Flies were then maintained in groups of 60 in individual

147 food vials and aged to 3-5 days old. We selected a single batch each day and ran all four

148 treatment groups separately in a randomized order, such that all flies assayed on a given day

149 were of the same batch and age. All experiments were run between 9am and 5pm. Before each

150 run, we measured the temperature at the center of each section along the gradient, then

151 transferred flies into the apparatus through a small hole located in the middle of the Plexiglas lid

152 where the temperature averaged $22.7^{\circ} \mathrm{C}$ (Supplemental Table S2). Flies were allowed to choose

153 their preferred temperatures along the gradient for 30 minutes (Matute et al. 2009; Goda et al.

154 2014; Arnold et al. 2019; Truitt et al. 2019). At the end of this period, we scored the numbers of

155 flies in each section. A small subset of flies located on the Plexiglas lid were removed from the

156 analysis (Goda et al. 2014). After each run, the thermal gradient was cleaned with ethanol and

157 allowed to dry.

158 For each genotype, we analyzed the $T_{p}$ data using generalized linear mixed models

159 (GLMMs) and a Poisson error structure in R (R Core Team 2018) with the "glmer" function in

160 the lme4 package (Bates et al. 2015). We treated $T_{p}$ of each fly as the dependent variable and

161 included infection status, sex, an infection-by-sex interaction, fly age (3, 4, or 5 days), and the

162 run order of each replicate over the course of the day $\left(1^{\text {st }}, 2^{\text {nd }}, 3^{\text {rd }}\right.$, or $\left.4^{\text {th }}\right)$ as fixed effects. The

163 replicate ID of each run was included as a random effect. We then assessed the significance of

164 fixed effects using an analysis of deviance with chi-squared tests. The $T_{p}$ data for some

165 genotypes more closely approximated a normal distribution (see Supplemental Table S3), so we

166 conducted an analogous set of tests using linear mixed models (LMMs) with the "Imer" function

167 in the lme4 package. Here, we assessed significance of fixed effects using an ANOVA with

168 Wald's chi-squared tests. The LMMs produced qualitatively similar results (Supplemental Table

$169 \mathrm{~S} 3$ ) to the GLMMs (Table 1), so only results from the GLMMs are presented in the main text.

170 A preliminary analysis of the data revealed that flies seemed to form a bimodal

171 distribution along the thermal gradient, with one cluster of flies located at the cold end of the

172 gradient (section 7) where temperatures averaged about $17^{\circ} \mathrm{C}$ (Supplemental Figure S3). Given

173 that $17^{\circ} \mathrm{C}$ generally falls below the average $T_{p}$ of Drosophila species reported in previous

174 experiments (Matute et al. 2009; Rajpurohit and Schmidt 2016; Arnold et al. 2019; Truitt et al.

175 2019), we hypothesized that flies were becoming immobilized in section 7 due to the cold 
temperature (see Dillon et al. 2009). A similar phenomenon has been identified for

Caenorhabditis elegans in assays of $T_{p}$ — the movement speed of $C$. elegans is dependent on et al. 2007). Thus, we removed the putatively immobilized flies in section 7 from each dataset and re-conducted our analyses. The analyses excluding section 7 are presented in the main text; however, including section 7 did not alter our findings of Wolbachia effects on $T_{p}$ (Supplemental

182 Table S4). We concluded that the dataset excluding immobilized flies represents a more

183 biologically accurate measure of $T_{p}$ for each genotype.

Wolbachia Sequencing and Phylogenomic Analysis

We conducted a phylogenomic analysis to characterize the evolutionary relationships among Wolbachia strains included in this study. We also tested whether Wolbachia effects on host $T_{p}$ exhibit phylogenetic signal (i.e. whether closely related Wolbachia strains have similar effects on $T_{p}$ ). We obtained Wolbachia sequences from publicly available genome assemblies, which included $w \mathrm{Ri}$ (Klasson et al. 2009), wHa (Ellegaard et al. 2013), wMau (Meany et al. 2019), and $w$ Yak and $w$ Tei (Cooper et al. 2019). We also obtained raw Illumina reads for a $w$ Sh-

192 infected $D$. sechellia individual from a previously published dataset (Accession SRX3029362;

193 Schrider et al. 2018). Importantly, two divergent Wolbachia strains may infect D. sechellia: A-

194 group $w$ Sh and B-group $w$ Sn. In nature, $w$ Sh singly infects some individuals, but it also occurs as 195 a co-infection with $w$ Sn (Rousset and Solignac 1995). We confirmed that our D. sechellia genotype (Pmuseumbananal) is singly infected with $w$ Sh using qPCR primers described below,

197 which can distinguish between A-group and B-group Wolbachia. Finally, we sequenced our 198 wMelCS- and wMel-infected D. melanogaster genotypes (Canton S Berkeley and PC75,

199 respectively) to compare the sequence similarity of our variants of these strains to those used in 200 the prior assay of $T_{p}$ by Truitt et al. (2019) (Chrostek et al. 2013).

Tissue samples for genomic DNA were extracted using a DNeasy Blood \& Tissue Kit

202 (Qiagen). DNA quantity was tested on a Nanodrop (Implen) and total DNA was quantified by 203 Qubit Fluorometric Quantitation (Invitrogen). DNA was cleaned using Agencourt AMPure XP

204 beads (Beckman Coulter, Inc.) following manufacturers' instructions, and eluted in $50 \mu 11 \times \mathrm{TE}$ 205 buffer for shearing. DNA was sheared using a Covaris E220 Focused Ultrasonicator (Covaris 206 Inc.) to a target size of 400 bp. We prepared libraries using NEBNext ${ }^{\circledR}$ Ultra ${ }^{\mathrm{TM}}$ II DNA Library 
207 Prep with Sample Purification Beads (New England BioLabs). Final fragment sizes and

208 concentrations were confirmed using a TapeStation 2200 system (Agilent). We indexed samples

209 using NEBNext ${ }^{\circledR}$ Multiplex Oligos for Illumina ${ }^{\circledR}$ (Index Primers Set 3 \& Index Primers Set 4),

210 and $10 \mu \mathrm{L}$ of each sample were shipped to Novogene (Sacramento, CA, USA) for sequencing

211 using Illumina HiSeq 4000, generating paired-end 150 bp reads.

212 Reads were trimmed using Sickle version 1.33 (Joshi et al. 2011) and assembled using

213 ABySS version 2.0.2 (Jackman et al. 2017). $K$ values of 71, 81, and 91 were used, and scaffolds

214 with the best nucleotide BLAST matches to known Wolbachia sequences with E-values less than

$21510^{-10}$ were extracted as the draft Wolbachia assemblies. For each genotype, we chose the

216 assembly with the highest N50 and the fewest scaffolds (Supplemental Table S5). The $w$ MelCS,

$217 w \mathrm{Mel}$, and $w$ Sh genomes, along with the five previously published genomes were annotated

218 using Prokka version 1.11, which identifies homologs to known bacterial genes (Seemann 2014).

219 To avoid pseudogenes and paralogs, we only used genes present in a single copy with no

220 alignment gaps in all of the genome sequences. Genes were identified as single copy if they

221 uniquely matched a bacterial reference gene identified by Prokka. By requiring all homologs to

222 have identical length in all of the Wolbachia genomes, we removed all loci with indels. A total of

223214 genes totaling 181,488 bp met these criteria.

224 We also repeated this analysis to include the $w \mathrm{MelCS}$ and $w \mathrm{Mel}$ genomes used in Truitt

225 et al. (2019). Here, we restricted our analysis to only wMelCS and wMel Wolbachia, with the

226 goal of comparing sequence similarity between the variants used in this study to those from

227 Truitt et al. (2019). Given that many loci accumulate indels over time, the number of loci

228 included in this analysis of wMel-like Wolbachia was relatively high, with a total of 720 genes

229 totaling 733,923 bp that met our criteria. Based on these 720 genes, our wMelCS variant

230 infecting the Canton S Berkeley genotype was identical to the $w$ MelCS variant used in Truitt et

231 al. (2019). Our $w \mathrm{Mel}$ variant infecting the PC75 genotype was also highly similar to $w$ Mel used

232 in Truitt et al. (2019), with only $0.000016 \%$ third-position pairwise differences (only 4 out of

233244,641 third-codon positions).

234 We estimated a Bayesian phylogram of the 214 genes from the eight different Wolbachia

235 strains using RevBayes 1.0.8 under the GTR $+\Gamma$ model partitioned by codon position (Höhna et

236 al. 2016). Four independent runs were performed for each phylogenetic tree we estimated, and in 
each instance, all four runs converged on the same topology. All nodes were supported with Bayesian posterior probabilities of 1 .

We used the resulting phylogram to test whether Wolbachia effects on host $T_{p}$ exhibit phylogenetic signal. For each genotype, we extracted the least square (LS) mean $T_{p}$ for infected and uninfected flies from the GLMMs, and then used the change in LS mean $T_{p}$ as a continuous character to calculate the maximum likelihood value of Pagel's lambda ( $\lambda$; Pagel 1999). A $\lambda$

243 value of 1 is consistent with a model of character evolution that entirely agrees with the 244 phylogeny (i.e. Wolbachia effects on $T_{p}$ are strictly proportional to relatedness), whereas a $\lambda$

245 value of 0 indicates that character evolution occurs independently of the phylogenetic

246 relationships (Freckleton et al. 2002). We used a likelihood ratio test to compare our fitted value

247 of $\lambda$ to a model assuming no phylogenetic signal $(\lambda=0)$ using the "phylosig" function in the $\mathrm{R}$

248 package phytools (Revell 2012). We also employed a Monte Carlo-based method to generate $24995 \%$ confidence intervals surrounding our $\lambda$ estimate using 1,000 bootstrap replicates in the $\mathrm{R}$ 250 package $p m c$ (Boettiger et al. 2012).

\section{Host Temperature Shift Experiments}

The thermal gradient assays revealed a main effect of Wolbachia on host $T_{p}$ for several genotypes. Interestingly, the host genotypes infected with A-group Wolbachia strains (w Ri, wHa, $w$ Sh, and $w$ Tei) preferred cooler temperatures than uninfected flies, whereas D. mauritiana - the only host genotype infected with B-group Wolbachia (wMau) - preferred a relatively warmer temperature. Truitt et al. (2019) speculated that the altered $T_{p}$ of infected flies represents a hostinduced behavior to reduce Wolbachia titer and ameliorate the negative effects of infection.

259 According to this hypothesis, shifting species infected with A-group Wolbachia to a cool 260 temperature should reduce Wolbachia titer in host bodies (i.e. behavioral chill), whereas shifting 261 D. mauritiana infected with $w$ Mau to a warm temperature should reduce Wolbachia titer (i.e.

262 behavioral fever). To test these predictions, we reared the five infected genotypes listed above at 263 an intermediate temperature of $21.5^{\circ} \mathrm{C}$. We separated female and male virgins, aged them to 3 264 days old at $21.5^{\circ} \mathrm{C}$, and then shifted them to either a cold $\left(18^{\circ} \mathrm{C}\right)$ or warm $\left(25^{\circ} \mathrm{C}\right)$ incubator for 26524 hours. Flies were separated by sex and maintained in groups of 40 in individual food vials 266 throughout the course of the experiment. Following 24 hours of the cold/warm temperature 267 treatment, flies were frozen in a $-80^{\circ} \mathrm{C}$ freezer for subsequent analysis of Wolbachia titer. This 
design enabled us to determine if an increase or decrease in $T_{p}$ of Wolbachia-infected adults alters Wolbachia titer.

We used qPCR to compare Wolbachia titer in flies shifted to $18^{\circ} \mathrm{C}$ vs. $25^{\circ} \mathrm{C}$. Flies from each temperature treatment were homogenized together in groups of 10 . The final samples

272 included 6 biological replicates for each sex and temperature treatment. DNA was extracted

273 using a DNeasy Blood \& Tissue Kit (Qiagen). We used a Stratagene Mx3000P (Agilent

274 Technologies) to amplify Drosophila- and Wolbachia-specific loci. In order to quantify titer of

275 the five different Wolbachia strains, we utilized multiple combinations of Drosophila and Wolbachia qPCR primers (Supplemental Table S6). Efficiency curves were generated to confirm

277 that each primer pair had adequate efficiency. All qPCR reactions were amplified using the 278 following cycling conditions: $50^{\circ} \mathrm{C}$ for 2 minutes, $95^{\circ} \mathrm{C}$ for 2 minutes, and then 40 cycles of $27995^{\circ} \mathrm{C}$ for 15 seconds, $58^{\circ} \mathrm{C}$ for 15 seconds, and $72^{\circ} \mathrm{C}$ for 1 minute. We used the average cycle 280 threshold $(C t)$ value of three technical replicates for each sample. We estimated relative 281 Wolbachia density as $2^{\Delta C t}$, where $\Delta C t=C t_{\text {Host }}-C t_{\text {Wolbachia }}$ (Pfaffl 2001). We then used a

282 Wilcoxon rank sum test to assess differences in titer between flies shifted to $18^{\circ}$ and $25^{\circ} \mathrm{C}$.

\section{RESULTS}

Wolbachia Infections Modify Host Temperature Preference

In total, we assayed the $T_{p}$ of 12,944 flies in 379 replicates on the thermal gradient.

287 Results from the eight different infected genotypes are summarized in Figure 1, Supplemental

288 Figure S4, and Table S7. Wolbachia infection status had a significant main effect on host $T_{p}$ for

289 five genotypes: $w$ Ri-infected $D$. simulans $\left(\chi^{2}=6.158, P=0.013\right)$, wHa-infected $D$. simulans $\left(\chi^{2}\right.$

$290=6.148, P=0.013), w$ Mau-infected $D$. mauritiana $\left(\chi^{2}=7.540, P=0.006\right), w$ Sh-infected $D$.

291 sechellia $\left(\chi^{2}=4.531, P=0.033\right)$, and $w$ Tei-infected $D$. teissieri $\left(\chi^{2}=8.264, P=0.004\right)$ (Table 1$)$.

292 These results were robust to whether the data were analyzed using GLMMs or LLMs

293 (Supplemental Table S3) or to whether we included flies that chose the coldest section of the 294 thermal gradient (section 7; Supplemental Table S4). Of the five Wolbachia strains with a 295 significant effect on $T_{p}$, all host genotypes infected with A-group Wolbachia preferred a cooler 296 temperature than uninfected flies (Figure 2): $w$ Ri-infected D. simulans preferred a LS mean 297 temperature of $21.72^{\circ} \mathrm{C} \pm 1.02$ ( \pm s.e.) compared to $23.12^{\circ} \mathrm{C} \pm 1.02$ for uninfected flies, $w \mathrm{Ha}-$ 298 infected $D$. simulans preferred a LS mean of $23.56^{\circ} \mathrm{C} \pm 1.01$ compared to the uninfected mean of 
Table 1. Results from the GLMMs. Statistically significant fixed effects at $P<0.05$ are marked in bold text with asterisks.

\begin{tabular}{|c|c|c|c|c|c|c|c|c|c|c|c|c|}
\hline \multirow[b]{2}{*}{$\begin{array}{l}\text { Explanatory } \\
\text { variable }\end{array}$} & \multicolumn{3}{|c|}{$w \mathbf{R i}$} & \multicolumn{3}{|c|}{$w \mathrm{Ha}$} & \multicolumn{3}{|c|}{$w$ MelCS } & \multicolumn{3}{|c|}{$w$ Mel } \\
\hline & coefficient & $\chi^{2}$ & $\begin{array}{c}P \\
\text { value }\end{array}$ & coefficient & $\chi^{2}$ & $\begin{array}{c}P \\
\text { value }\end{array}$ & coefficient & $\chi^{2}$ & $\begin{array}{c}P \\
\text { value }\end{array}$ & coefficient & $\chi^{2}$ & $\begin{array}{c}P \\
\text { value }\end{array}$ \\
\hline Infection Status & 0.069 & 6.158 & $0.013^{*}$ & 0.063 & 6.148 & $0.013^{*}$ & -0.017 & 1.285 & 0.257 & -0.004 & 0.031 & 0.860 \\
\hline Sex & -0.060 & 4.341 & $0.037^{*}$ & -0.070 & 6.907 & $0.009 *$ & -0.007 & 0.224 & 0.636 & -0.046 & 3.490 & 0.062 \\
\hline Age & -0.003 & 0.016 & 0.898 & -0.001 & 0.020 & 0.887 & -0.019 & 11.426 & $0.001 *$ & 0.012 & 2.251 & 0.134 \\
\hline Run Order & 0.001 & 0.013 & 0.909 & 0.009 & 1.002 & 0.317 & 0.011 & 4.914 & $0.027 *$ & 0.005 & 0.366 & 0.545 \\
\hline Infection * Sex & -0.013 & 0.099 & 0.754 & -0.016 & 0.186 & 0.666 & 0.002 & 0.005 & 0.943 & 0.021 & 0.368 & 0.544 \\
\hline Sample Size & 1015 & & & 857 & & & 1727 & & & 1341 & & \\
\hline
\end{tabular}

\begin{tabular}{|c|c|c|c|c|c|c|c|c|c|c|c|c|}
\hline \multirow[b]{2}{*}{$\begin{array}{l}\text { Explanatory } \\
\text { variable }\end{array}$} & \multicolumn{3}{|c|}{$w$ Mau } & \multicolumn{3}{|c|}{$w \mathrm{Sh}$} & \multicolumn{3}{|c|}{$w$ Yak } & \multicolumn{3}{|c|}{$w$ Tei } \\
\hline & coefficient & $\chi^{2}$ & $\begin{array}{c}P \\
\text { value }\end{array}$ & coefficient & $\chi^{2}$ & $\begin{array}{c}P \\
\text { value }\end{array}$ & coefficient & $\chi^{2}$ & $\begin{array}{c}P \\
\text { value }\end{array}$ & coefficient & $\chi^{2}$ & $\begin{array}{c}P \\
\text { value }\end{array}$ \\
\hline Infection Status & -0.091 & 7.540 & $0.006 *$ & 0.042 & 4.531 & $0.033^{*}$ & 0.002 & 0.007 & 0.936 & 0.038 & 8.264 & 0.004* \\
\hline Sex & -0.052 & 3.175 & 0.075 & 0.009 & 0.238 & 0.626 & -0.010 & 0.179 & 0.673 & -0.017 & 1.694 & 0.193 \\
\hline Age & -0.018 & 2.686 & 0.101 & 0.003 & 0.130 & 0.718 & 0.026 & 3.633 & 0.057 & -0.012 & 2.717 & 0.099 \\
\hline Run Order & 0.020 & 3.968 & $0.046 *$ & 0.011 & 3.187 & 0.074 & 0.009 & 1.320 & 0.251 & 0.001 & 0.086 & 0.770 \\
\hline Infection * Sex & 0.036 & 0.680 & 0.409 & -0.029 & 1.151 & 0.283 & 0.011 & 0.108 & 0.742 & 0.011 & 0.366 & 0.545 \\
\hline Sample Size & 818 & & & 1087 & & & 1056 & & & 2500 & & \\
\hline
\end{tabular}

$29924.89^{\circ} \mathrm{C} \pm 1.01, w$ Sh-infected $D$. sechellia preferred a LS mean of $23.32^{\circ} \mathrm{C} \pm 1.01$ compared to

300 the uninfected mean of $23.98^{\circ} \mathrm{C} \pm 1.01$, and $w$ Tei-infected $D$. teissieri preferred a LS mean of $22.70^{\circ} \mathrm{C} \pm 1.01$ compared to the uninfected mean of $23.70^{\circ} \mathrm{C} \pm 1.01$. In contrast, D. mauritana infected with B-group $w$ Mau preferred a warmer LS mean temperature of $21.15{ }^{\circ} \mathrm{C} \pm 1.01$ compared to the uninfected mean of $19.67^{\circ} \mathrm{C} \pm 1.02$.

In addition to Wolbachia infection status, we found other significant fixed effects on $T_{p}$. Sex had a significant main effect on $T_{p}$ for both the $w$ Ri-infected $D$. simulans $\left(\chi^{2}=4.341, P=\right.$ $0.037)$ and $w$ Ha-infected $D$. simulans $\left(\chi^{2}=6.907, P=0.009\right)$ (Table 1). For both of these $D$. simulans genotypes, males preferred cooler temperatures than females, regardless of infection status (Supplemental Figure S4). For the $w$ Ri genotype, males preferred an LS mean temperature

310 preferred an LS mean temperature of $23.29^{\circ} \mathrm{C} \pm 1.01$ compared to the female mean of $25.18^{\circ} \mathrm{C} \pm$

311 1.01. We also found a significant effect of fly age on $T_{p}$ for $w$ MelCS-infected $D$. melanogaster

$312\left(\chi^{2}=11.426, P=0.001\right)$, such that older flies tended to prefer cooler temperatures. Finally, we

313 found that the run order each day had a significant effect on $T_{p}$ for the $w$ MelCS-D. melanogaster

$314\left(\chi^{2}=4.914, P=0.027\right)$ and the $w$ Mau- $D$. mauritiana genotypes $\left(\chi^{2}=3.968, P=0.046\right)$. In both

315 instances, flies assayed earlier in the day tended to prefer cooler temperatures. Interestingly, we

316 only detected a main effect of $w \mathrm{Mau}$ on $D$. mauritiana $T_{p}$ after accounting for run order- $-w \mathrm{Mau}$ 
Figure 1. Box plots showing temperature preference $\left(T_{p}\right)$ for uninfected (U) and infected (I) flies of each genotype. Asterisks denote a significant main effect of Wolbachia infection on $T_{p}$ from the GLMMs (Table 1). Individual points are jittered to show overlap. Similar plots including the coldest section of the thermal gradient (section 7) are shown in Supplemental Figure S3.

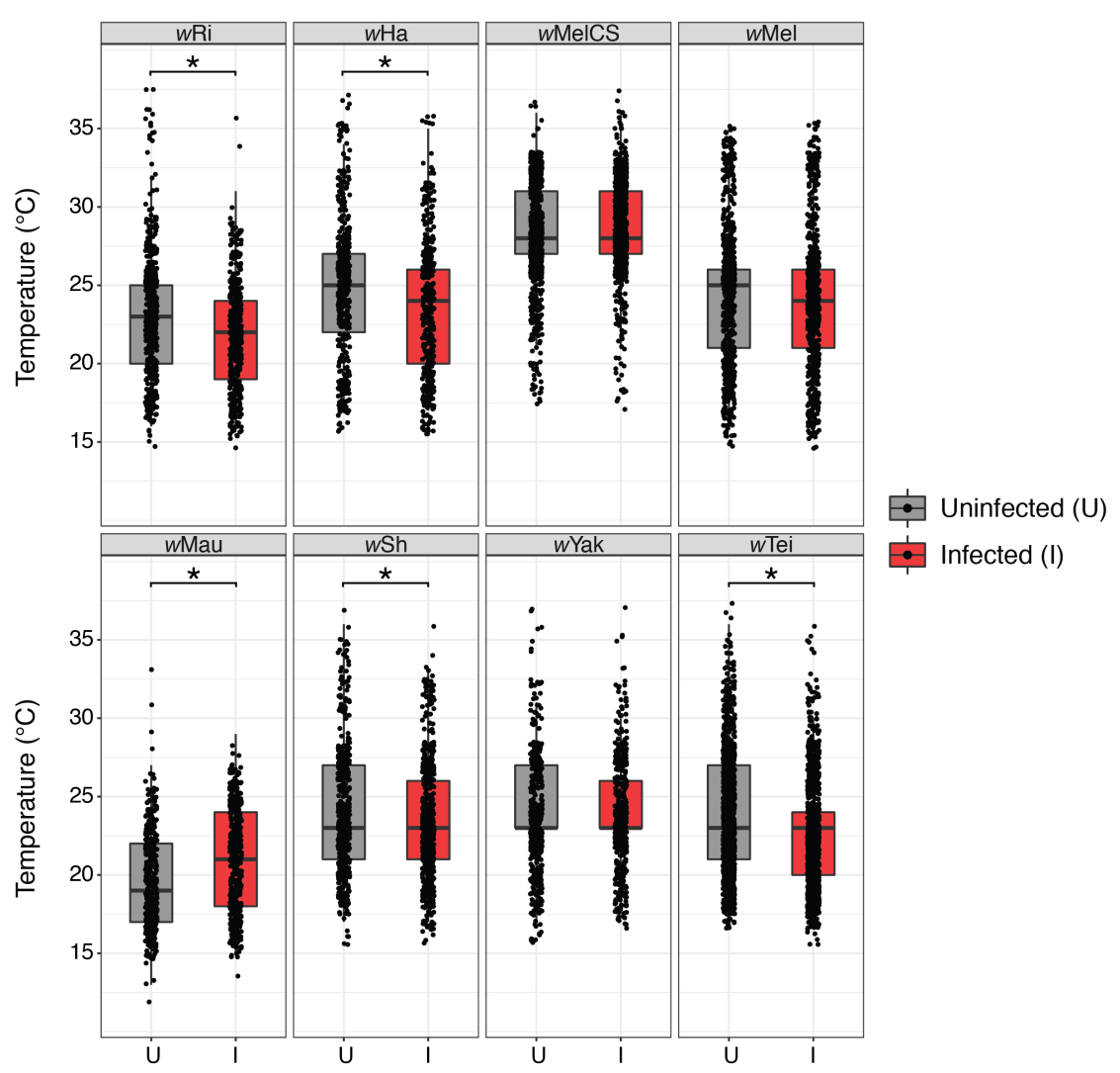

only had a marginal effect on $T_{p}$ when we removed run order from the model $\left(\chi^{2}=3.549, P=\right.$ $0.060)$.

Next, we used the Wolbachia phylogram (Figure 2) to test whether Wolbachia effects on host $T_{p}$ exhibit phylogenetic signal. Our fitted $\lambda$ value was high $(\lambda=0.778[0,0.984])$, but not significantly different from a model assuming no phylogenetic signal (likelihood ratio test, $P=$ 0.203). The large confidence intervals associated with our $\lambda$ estimate are likely due to the small number of strains included in the phylogram $(N=8)$. Further exploration of the distribution of $\lambda$ estimates from the 1,000 bootstrap replicates showed a large number of near-zero values (Supplemental Figure S5). Small phylogenies are likely to generate near-zero $\lambda$ values by random chance, not necessarily because the phylogeny is unimportant for trait evolution (Boettiger et al. 2012). To test whether larger phylogenies increase the accuracy of parameter estimation, we simulated trees with an increasing number of strains $(N=25,50$, and 100) and our $\lambda$ estimate of 0.778 using the "sim.bdtree" and "sim.char" functions in the geiger R package (Harmon et al. 2008). See Supplemental Figure S5 for an extended description of the simulations. The simulated trees suggest that at least 50 strains are required to statistically distinguish $\lambda \approx 0.8$ from zero. The $N=25$ tree had a fitted $\lambda$ with extremely large confidence 


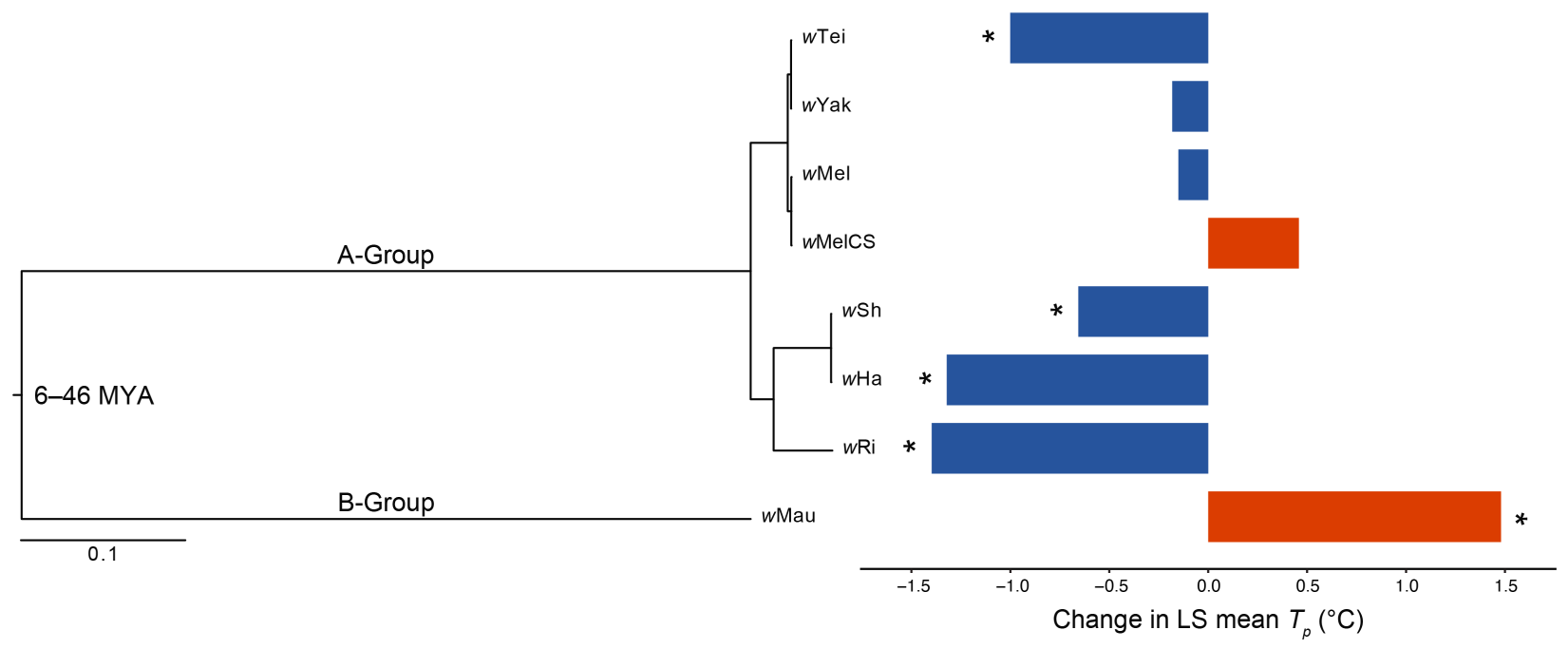

Figure 2. Estimated Bayesian phylogram for A- and B-group Wolbachia strains examined in this study. The phylogram was estimated with 214 single-copy genes of identical length in all of the genomes, spanning 181,488 bp. All nodes have Bayesian posterior probabilities of 1 . To the right, the change in least square (LS) mean $T_{p}$ between uninfected and infected flies is shown for each Wolbachia strain. LS means were generated from GLMMs (Table 1), and strains with a significant main effect on $T_{p}$ are marked with asterisks. Divergence time estimates (MYA) for A- and B-group Wolbachia are from Meany et al. (2019).

333 intervals $(\lambda=0.886[0,1])$, whereas the $N=50$ tree had a $\lambda$ estimate that does not overlap with 334 zero $(\lambda=0.860[0.376,0.977])$. Together, these results suggest that Wolbachia effects on host $T_{p}$ 335 may exhibit phylogenetic signal, but our phylogeny is too small to distinguish statistically significant values of $\lambda$.

24-Hour Temperature Shifts Generally Do Not Alter Wolbachia Titer

We tested whether shifting infected flies from an intermediate temperature towards their preferred temperature for 24 hours significantly alters Wolbachia titer. Results are summarized in Figure 3 and Supplemental Table S8. For $w$ Ri-infected D. simulans, Wolbachia titer did not differ between the 24-hour cold and warm temperature treatments for females $(W=12, P=$

343 1.000) or males ( $W=19, P=0.937)$. Similarly, for $w$ Ha-infected $D$. simulans, titer did not differ

344 between the temperature treatments for females $(W=13, P=0.485)$ or males $(W=18, P=$

345 1.000). We also observed no significant difference in titer between temperature treatments for $346 w$ Mau-infected D. mauritiana females $(W=14, P=0.589)$ or males $(W=14, P=0.589)$. For $347 \quad w$ Sh-infected $D$. sechellia, we detected no difference in Wolbachia titer between females from 348 each temperature treatment ( $W=13, P=0.485$ ); however, we found that males significantly 349 differed in titer between cold and warm treatments $(W=32, P=0.026)$. Male $D$. sechellia 

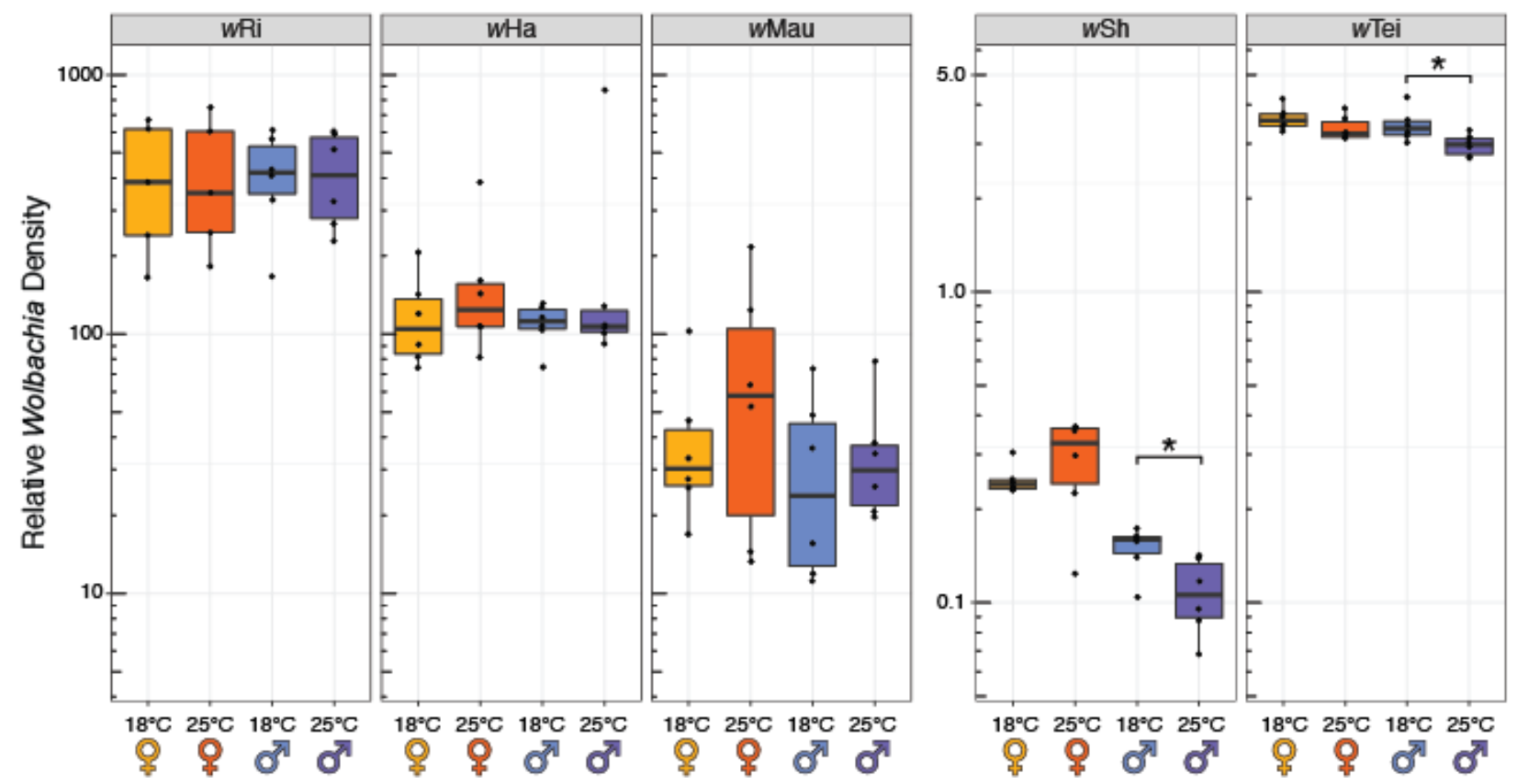

Figure 3. Boxplots of relative Wolbachia density from temperature shift experiments for the five Wolbachia strains showing main effects on host $T_{p}$ (Table 1). Relative Wolbachia density is shown for virgin females ( $(q)$ and males $\left(\delta^{\lambda}\right)$ shifted to cold $\left(18^{\circ} \mathrm{C}\right)$ and warm $\left(25^{\circ} \mathrm{C}\right)$ temperatures for 24 hours. Graphs are separated into strains with high titer $(w \mathrm{Ri}, w \mathrm{Ha}$, and $w \mathrm{Mau})$ and low titer ( $w \mathrm{Sh}$ and $w \mathrm{Tei})$. Asterisks denote significant differences in titer between males shifted to $18^{\circ} \mathrm{C}$ and $25^{\circ} \mathrm{C}$ based on Wilcoxon rank sum tests.

shifted to $18^{\circ} \mathrm{C}$ had a higher median relative Wolbachia density $\left(2^{\Delta C t}=0.16\right)$ than males shifted to $25^{\circ} \mathrm{C}\left(2^{\Delta C t}=0.11\right)$. This pattern is counter to the behavioral chill hypothesis proposed by Truitt et al. (2019), because $w$ Sh-infected D. sechellia preferred a cooler temperature than uninfected flies, and shifting infected males to a cool temperature resulted in increased Wolbachia titer. We found the same pattern for $w$ Tei-infected D. teissieri. While we detected no difference in Wolbachia titer between the treatments for females $(W=28, P=0.132)$, males differed significantly in titer between the cold and warm treatments $(W=31, P=0.041)$. As with D. sechellia, male D. teissieri shifted to $18^{\circ} \mathrm{C}$ had a higher median relative Wolbachia density $\left(2^{\Delta C t}=3.36\right)$ than males shifted to $25^{\circ} \mathrm{C}\left(2^{\Delta C t}=2.98\right)$.

\section{DISCUSSION}

Our analyses suggest Wolbachia may generally influence host thermoregulatory behavior. Five of the eight Wolbachia strains we assayed had a significant effect on host $T_{p}: w \mathrm{Ri}$ in D. simulans, wHa in D. simulans, w Mau in D. mauritiana, wSh in D. sechellia, and $w$ Tei in D. teissieri. In contrast to past reports (Arnold et al. 2019; Truitt et al. 2019), we found no evidence 
effects (see below). Temperature is considered a major ecological factor limiting the distribution of Drosophila (Hoffmann et al. 2002; Umina et al. 2005; Kellermann et al. 2009, 2012; Hoffmann 2010; Adrion et al. 2015; Rajpurohit and Schmidt 2016) and many other species (Crisp et al. 2009; Tittensor et al. 2010; Quintero and Wiens 2013). Body temperature is an important determinant of performance and fitness (Siddiqui and Barlow 1972; Huey and Berrigan 2001; Chown and Nicolson 2004; Martin and Huey 2008; Angilletta 2009; Cooper et al. 2012; Huey et al. 2012; Hoekstra et al. 2013; Condon et al. 2014), and ectotherms depend on thermoregulatory behavior to maintain body temperature within a narrow range (Angilletta et al. 2004; Martin and Huey 2008; Dillon et al. 2009; Garrity et al. 2010; Hoffmann and Sgro 2011; Rajpurohit and Schmidt 2016). Given that Wolbachia have spread through most insect species and other ectotherms (Werren et al. 2008; Zug and Hammerstein 2012; Weinert et al. 2015), our results motivate additional analyses of Wolbachia effects on $T_{p}$ and thermoregulation of other 378 host taxa.

Interestingly, hosts infected with A-group Wolbachia generally preferred cooler temperatures, whereas D. mauritiana infected with the B-group wMau preferred warmer temperatures. Nonetheless, we did not find sufficient evidence to demonstrate these Wolbachia effects exhibit phylogenetic signal (Figure 2$)$. The fitted $\lambda=0.778$ was not significant $(P=$

383 0.203), but our simulations suggest this may be due to a small phylogeny (Supplemental Figure

384 S5). Analyses of additional Wolbachia, and specifically B-group strains, are needed to test

385 whether A- and B-group Wolbachia generally differ in how they influence host $T_{p}$.

386 Unfortunately, the only other B-group strains that infect hosts in the D. melanogaster subgroup

387 (wNo and $w \mathrm{Sn}$ ) almost always occur as co-infections with other Wolbachia (Meany et al. 2019).

$388 w$ No co-occurs with wHa in D. simulans (O’Neill and Karr 1990; Mercot et al. 1995; Rousset

389 and Solignac 1995; James et al. 2002), and wSn co-occurs with wSh in D. sechellia (Giordano et

390 al. 1995; Rousset and Solignac 1995). Naturally sampled genotypes that are singly infected with 391 these strains are required to further assess B-group Wolbachia effects on host $T_{p}$ in this subgroup.

392 Our simulations suggest that a relatively large number of strains $(N=50)$ are required to

393 rigorously test whether Wolbachia effects on $T_{p}$ exhibit phylogenetic signal (Supplemental

394 Figure S5). Unfortunately, measuring host $T_{p}$ for this many Wolbachia-infected and -uninfected 395 genotypes would be challenging. 
The phylogenetic analysis also showed that, in some instances, closely related Wolbachia strains may have different effects. For example, $w$ Tei and $w$ Yak diverged only about 1,500 years ago and share very high sequence similarity $(0.0039 \%$ third-position pairwise differences; Cooper et al. 2019), yet $w$ Tei altered $T_{p}$ of D. teissieri and $w$ Yak had no effect on $D . y a k u b a$ (Figure 2). Similarly, $w \mathrm{Ha}$ and $w \mathrm{Sh}$ have high sequence similarity according to our analysis $(0.00008 \%$ third-position pairwise differences) and likely spread recently via introgression (Ballard 2000; Meany et al. 2019), yet our mean estimates of titer for wHa in D. simulans (157.1) and $w$ Sh in D. sechellia (0.2) differ by nearly three orders of magnitude (Figure 3 ). Host background effects may explain why closely related Wolbachia can have variable effects on their hosts. In a similar manner, host genomes can modify Wolbachia titer (Funkhouser-Jones et al. 2018), maternal Wolbachia transmission (Serbus and Sullivan 2007), components of host fitness (Fry et al. 2004; Dean 2006; Gruntenko et al. 2019), and the strength of cytoplasmic incompatibility (Reynolds and Hoffmann 2002; Cooper et al. 2017).

We predict that host backgrounds could explain why we found no effects of Wolbachia

411 et al. (2019) found a small, yet statistically significant, reduction in $T_{p}$ of $w$ MelCS-infected $D$.

412 melanogaster $\left(25.06^{\circ} \mathrm{C}\right.$ vs. $25.78^{\circ} \mathrm{C}$ for uninfected flies), and Truitt and colleagues (2019) found

413 that a $w$ MelCS variant identical to our own (according to 720 genes totaling 733,923 bp) reduced

414 D. melanogaster $T_{p}$ by nearly $4^{\circ} \mathrm{C}$. The effect size reported by Truitt et al. (2019) is more than

415 two and a half times greater than the largest effect we document here for any strain, and more

416 than five times larger than the reduction in $T_{p}$ observed by Arnold and colleagues (2019). The

$417 w$ MelCS variant assayed in Truitt et al. (2019) was introduced into the foreign DrosDel $w^{1118}$

418 isogenic background using chromosome replacement (Chrostek et al. 2013), while Arnold et al.

419 (2019) used a standard Oregon $R C$ line that was orginally established in the 1920s (Hartl and

420 Jungen 1979; Riegler et al. 2005; Hedges et al. 2008). Our wMelCS-infected genotype is a sub-

421 strain of the Canton Special line that was also established in the 1920s (Stern 1943; Stern and

422 Schaeffer 1943), and sub-strains of Canton Special can exhibit phenotypic variation due to

423 founder effects and drift (Colomb and Brembs 2014). Future analyses should use contemporary

424 isofemale lines to generate reciprocally introgressed host and Wolbachia genotypes and dissect

425 the relative contributions of host and Wolbachia genomes to $T_{p}$, titer, and other traits. 
Our temperature shift experiments indicate that changes to $T_{p}$ of infected host genotypes generally do not alter Wolbachia titer, but in a few instances, reductions in $T_{p}$ seem to increase Wolbachia replication within host bodies (Figure 3). wSh-infected D. sechellia and $w$ Teiinfected D. teissieri preferred cooler temperatures than uninfected flies (Figure 2), and infected males reared at $21.5^{\circ} \mathrm{C}$ had significantly higher Wolbachia titer when shifted to a cold $18^{\circ} \mathrm{C}$ treatment for 24 hours, compared to a warm $25^{\circ} \mathrm{C}$ treatment (Figure 3). Moghadam et al. (2018) reported a similar effect of cold temperature on Wolbachia titer in male D. melanogaster, in which males developed at $13^{\circ} \mathrm{C}$ had higher microbial diversity and a higher relative abundance of Wolbachia than males developed at $23^{\circ}$ and $31^{\circ} \mathrm{C}$ (based on $16 \mathrm{~S}$ rRNA sequencing). Our results are consistent with a hypothesis of parasite manipulation, in which Wolbachia alter host behavior to seek environmental conditions that promote Wolbachia growth and transmission (Poulin 2010; De Roode and Lefèvre 2012; Curtis 2014; Heil 2016; Vale et al. 2018; Weinersmith 2019). However, we found no temperature-associated increases in titer for $w$ Shand $w$ Tei-infected females or for any other Wolbachia strains we assessed. Other studies have also reported male-biased environmental effects on Wolbachia titer (Correa and Ballard 2012;

441 Foo et al. 2019; Hague et al. 2020); for example, our own work demonstrated that maternal 442 transmission of $w$ Yak to sons is more efficient than to daughters when D. yakuba mothers are 443 reared in cold $20^{\circ} \mathrm{C}$ conditions (Hague et al. 2020).

$444 \quad$ Our findings do not provide support for the hypothesis proposed by Truitt et al. (2019)

445 that modifications to $T_{p}$ represent an adaptive host response (e.g., behavioral chill) to reduce

446 Wolbachia titer and mitigate the negative effects of infection. In particular, Truitt et al. (2019)

447 speculated that $w \mathrm{MelCS}$ is costly to the host because the strain has a higher titer and growth rate 448 than $w \mathrm{Mel}$ (Chrostek et al. 2013), and wMelCS-infected D. melanogaster prefer colder

449 temperatures to reduce Wolbachia titer and limit costly infections. The authors did not measure $450 w$ MelCS titer or estimate host fitness components to test this hypothesis (Truitt et al. 2019). We 451 found no effects of $w \mathrm{MelCS}$ or $w \mathrm{Mel}$ on $T_{p}$ of $D$. melanogaster and no evidence that decreases in $452 T_{p}$ reduce Wolbachia titer for other infected systems (Figure 3). Nonetheless, the observation that 453 most Wolbachia-infected hosts have altered $T_{p}$ motivates future analyses of host behaviors that 454 might mitigate negative aspects of infection, especially because Wolbachia can have costly 455 effects on hosts (Hoffmann et al. 1990; Stouthamer and Luck 1993; Turelli and Hoffmann 1995; 456 Weeks et al. 2007). We found no association between changes to $T_{p}$ and a decrease in adult 
Wolbachia titer, but perhaps infected females seek oviposition sites that reduce the efficiency of Wolbachia maternal transmission (Dillon et al. 2009). Wolbachia maternal transmission seems to be influenced by relatively cold $20^{\circ} \mathrm{C}$ temperatures in Drosophila (Hague et al. 2020) and hot temperatures in mosquitoes (Ross et al. 2017, 2019a). Future work should test whether rearing infected hosts at their $T_{p}$ influences Wolbachia titer.

Our results add to mounting literature showing that temperature is an important abiotic factor mediating interactions between Wolbachia and their hosts (Charlesworth et al. 2019). In particular, Wolbachia titer seems to be especially sensitive to temperature (Clancy and Hoffmann 1998; Mouton et al. 2006, 2007; Bordenstein and Bordenstein 2011; Ross et al. 2017, 2019a; Sumi et al. 2017; Hague et al. 2020). Our 24-hour temperature shift experiments suggest Wolbachia titer can change over very short time periods due to environmental conditions. Mouton et al. (2006) reported a similar result in which Leptopilina heterotoma infected with $w$ Lhet experienced a significant increase in Wolbachia titer over the course of a single host generation when mothers were reared at $20^{\circ} \mathrm{C}$ and daughters developed at $26^{\circ} \mathrm{C}$. Temperatureinduced changes to Wolbachia titer are likely to have cascading effects, given that titer

472 influences other host phenotypes (López-Madrigal and Duarte 2019). For example, exposure to

473 heat stress is associated with correlated declines in Wolbachia titer and the severity of cytoplasmic incompatibility in wMel-transinfected Ae. aegypti (Ross et al. 2017, 2019a). In

475 Drosophila hosts, temperature has been shown to modify the strength of cytoplasmic

476 incompatibility (Hoffmann et al. 1986, 1990; Clancy and Hoffmann 1998; Reynolds and

477 Hoffmann 2002), maternal transmission (Turelli and Hoffmann 1995; Hague et al. 2020), and

478 host fitness effects (Olsen et al. 2001; Versace et al. 2014; Kriesner et al. 2016). Clearly, more 479 work on how temperature influences Wolbachia-host interactions is needed.

\section{Conclusion}

482 We show that A- and B-group Wolbachia induce changes to host $T_{p}$, and short 24-hour 483 shifts in temperature can increase titer in some Wolbachia-infected males. Behavioral changes 484 like these are likely to have fundamental consequences for host physiology and 485 thermoregulation. Wolbachia also modify a range of other ecologically important host traits in 486 Drosophila species, including reproduction (Hoffmann and Turelli 1997; Werren et al. 2008), 487 virus blocking (Hedges et al. 2008; Teixeira et al. 2008; Osborne et al. 2009; Martinez et al. 
2014), nutrient provisioning (Brownlie et al. 2009; Newton and Rice 2020), and activity levels (van Houte et al. 2013; Bi and Wang 2019). Given that $T_{p}$ and many other Drosophila traits vary clinally (Hoffmann and Weeks 2007; Rajpurohit and Schmidt 2016), future studies should consider the role of Wolbachia in classic Drosophila clines (Adrion et al. 2015). For example, $w \mathrm{Mel}$ infection frequencies (Kriesner et al. 2016) and the $T_{p}$ of D. melanogaster (Rajpurohit and Schmidt 2016) both vary spatially in eastern North America.

Understanding the impact of Wolbachia on host performance and fitness is crucial for predicting evolutionary outcomes of Wolbachia-host interactions (Ross et al. 2019b). The initial spread of Wolbachia through new host populations is driven by beneficial effects on host fitness that cause infections to deterministically spread from low initial frequencies (Caspari and Watson 1959; Hoffmann et al. 1990; Barton and Turelli 2011). Yet, strong positive host effects have not been directly connected to spread in nature for any Wolbachia-infected host species (Cooper et al. 2017; Shi et al. 2018; Meany et al. 2019; Ross et al. 2019b); although, wRi recently evolved to confer a $10 \%$ fecundity advantage to $D$. simulans (Weeks et al. 2007). Few data exist for other components of host fitness, but protection from viruses and nutrient provisioning remain candidates for potential host benefits (Hedges et al. 2008; Teixeira et al. 2008; Brownlie et al. 2009; Osborne et al. 2009; Martinez et al. 2014; Nikoh et al. 2014; Newton and Rice 2019; but see Shi et al. 2018). Basic research on how Wolbachia modify different components of host fitness, like the effects on $T_{p}$ reported here, represents a key step to uncovering how Wolbachia benefit hosts and spread to become a global pandemic.

\section{ACKNOWLEDGEMENTS}

We thank Tim Wheeler for assistance in the lab and Will Conner for help with

512 Begun, Michael Turelli, and Daniel Matute kindly provided flies used in this study. The Cooper

513 lab group, Michael May, and Gregg Thomas provided valuable feedback that improved the

514 quality of the manuscript. We thank the Genomics Core and the Environmental Control for

515 Organismal Research (ECOR) Laboratories at the University of Montana for their support. 
bioRxiv preprint doi: https://doi.org/10.1101/2020.06.11.146977; this version posted June 12, 2020. The copyright holder for this preprint (which was not certified by peer review) is the author/funder, who has granted bioRxiv a license to display the preprint in perpetuity. It is made available under aCC-BY-NC-ND 4.0 International license.

\section{FUNDING}

$520 \quad$ Research reported in this publication was supported by the National Institute of General

521 Medical Sciences of the National Institutes of Health (NIH) under award number R35GM124701

522 to BSC. 


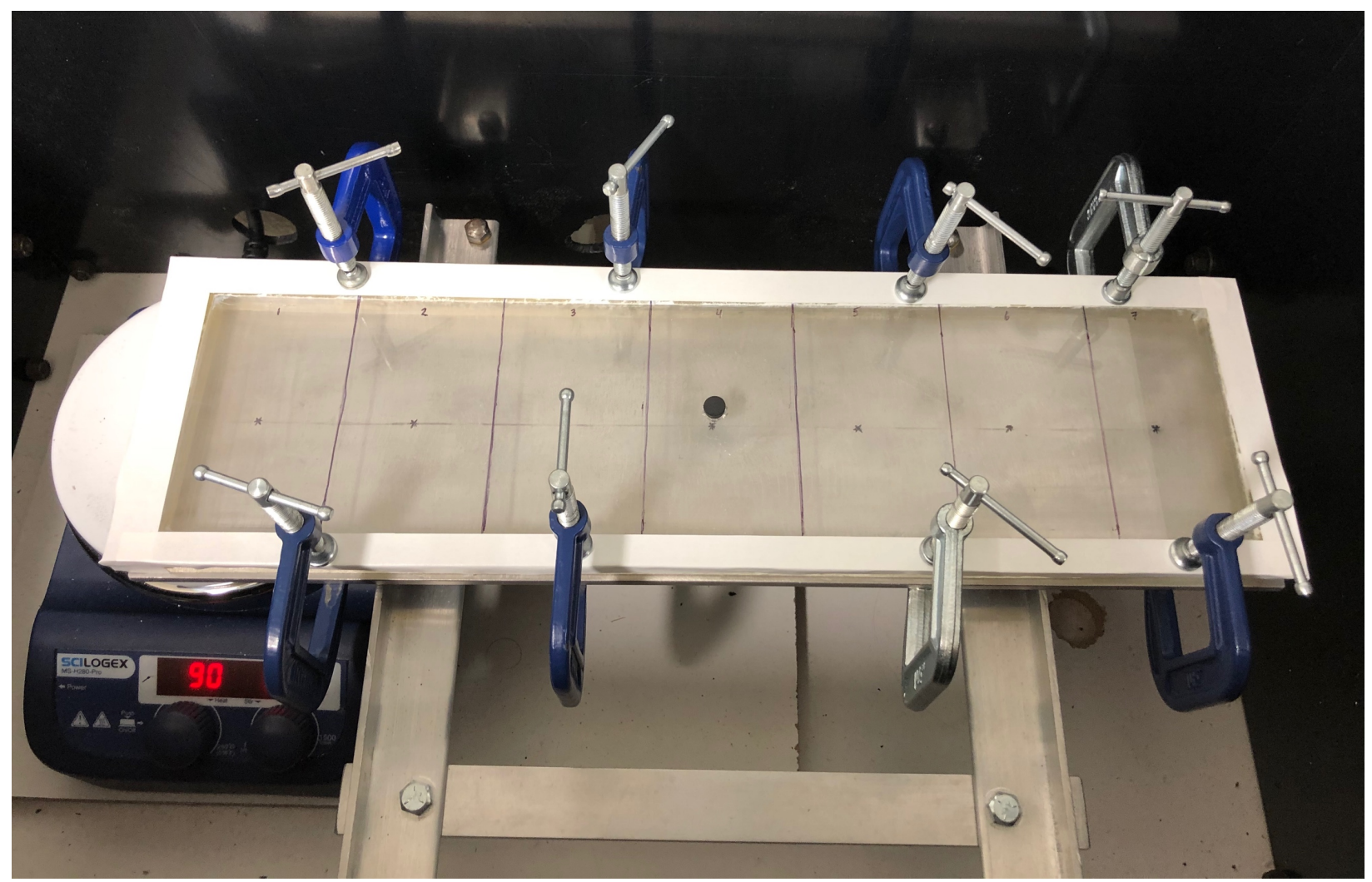

Supplemental Figure S1. The thermal gradient apparatus is composed of a $44 \times 13 \times 1 \mathrm{~cm}$ aluminum plate and a $1 \mathrm{~cm}$-high removable Plexiglas lid. The thermal gradient is subdivided into seven 10 x $6 \mathrm{~cm}$ sections (Supplemental Figure S2, Table S2). 
bioRxiv preprint doi: https://doi org/10.1101/2020.06.11.146977; this version posted June 12, 2020. The copyright holder for this preprint (which was not certified by peer review) is the author/funder, who has granted bioRxiv a license to display the preprint in perpetuity. It is made available under aCC-BY-NC-ND 4.0 International license.

530

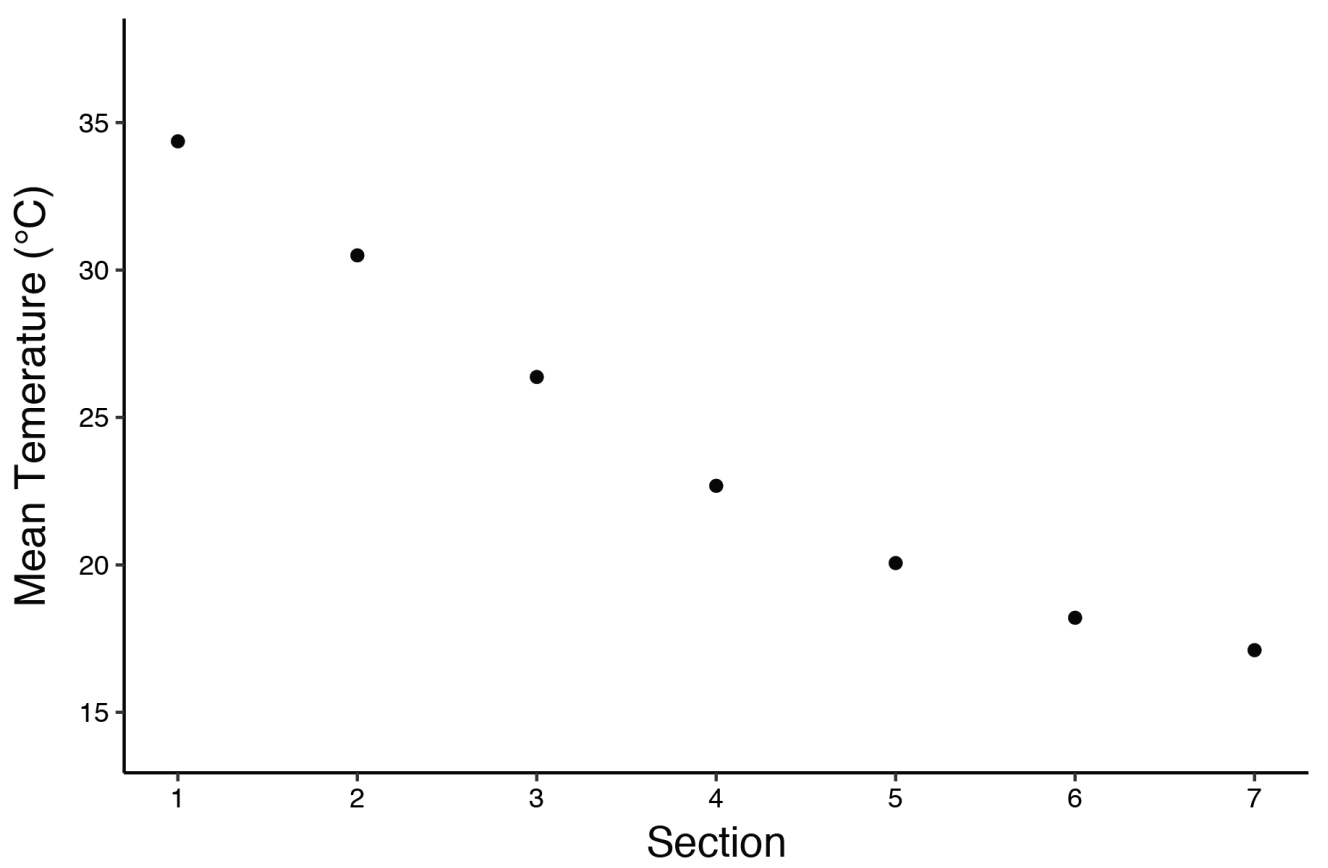

533 Supplemental Figure S2. Mean temperature of each section on the thermal gradient apparatus. 534 Mean and standard errors are presented in Supplemental Table S2. 


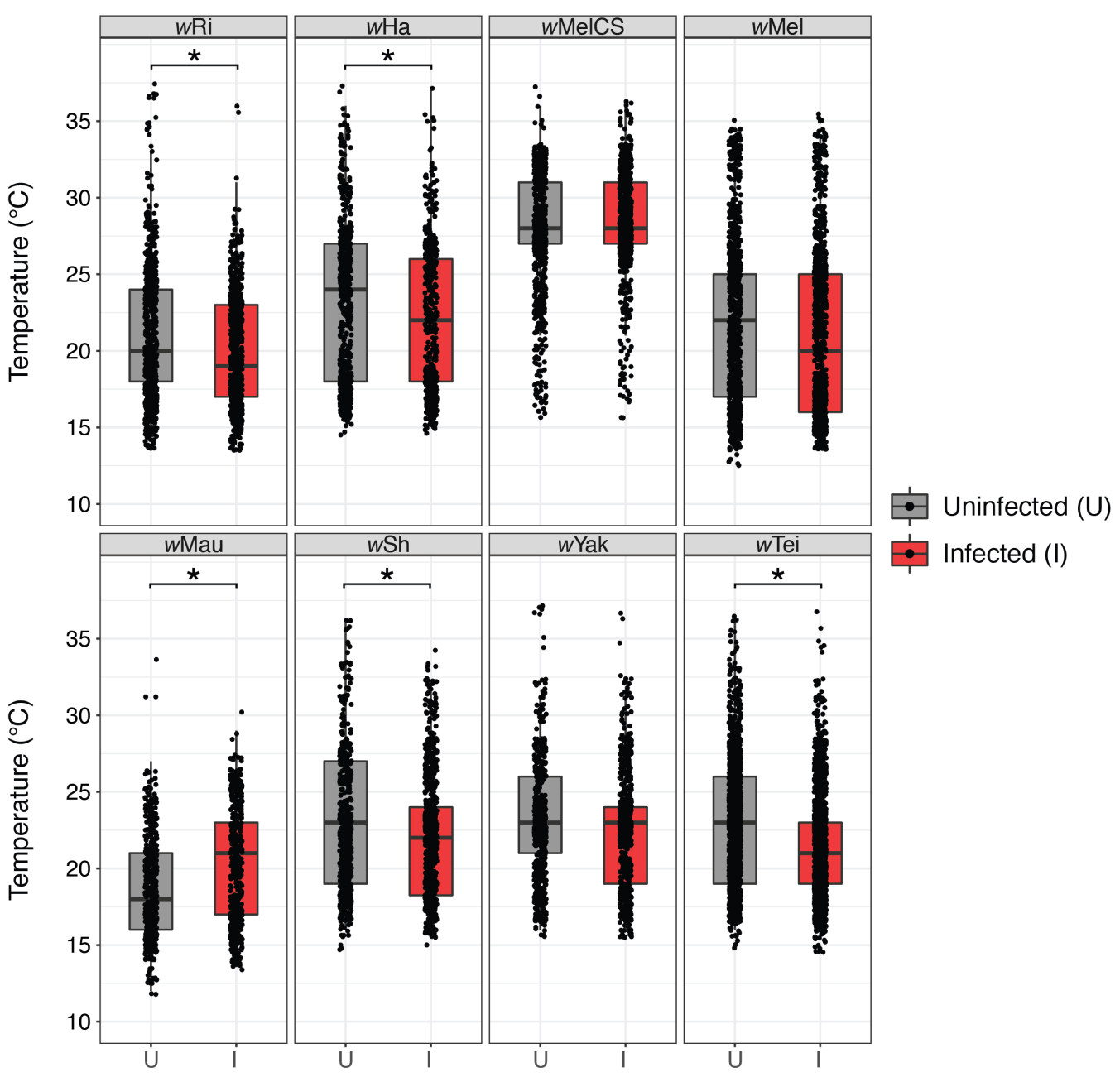

Supplemental Figure S3. Box plots showing temperature preference $\left(T_{p}\right)$ for uninfected (U) and infected (I) flies of each genotype when the coldest section of the thermal gradient (section 7) is included. Asterisks denote a significant main effect of Wolbachia infection on $T_{p}$ from the GLMMs (Supplemental Table S4). Individual points are jittered to show overlap. 


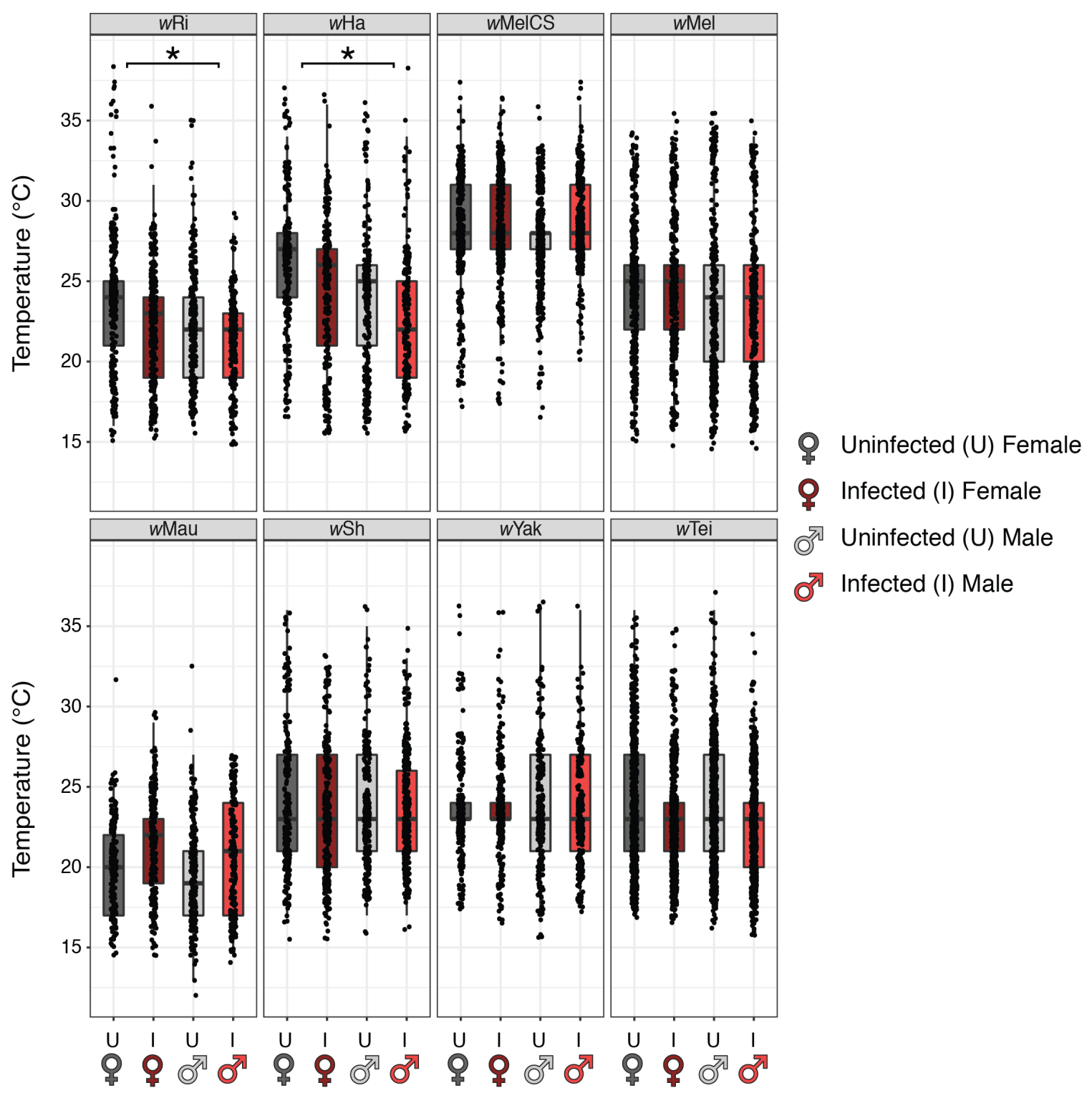

Supplemental Figure S4. Box plots showing temperature preference $\left(T_{p}\right)$ for uninfected (U) and infected (I) flies of each genotype, separated by sex. Asterisks denote a significant main effect of sex on $T_{p}$ from the GLMMs (Table 1). Individual points are jittered to show overlap. The coldest section of the thermal gradient apparatus (section 7) is removed from the dataset. 


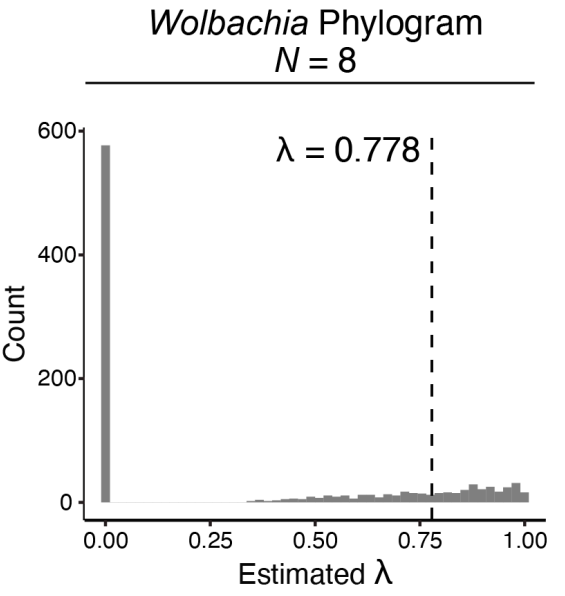

$\bar{\lambda}=0.327[0,0.984]$

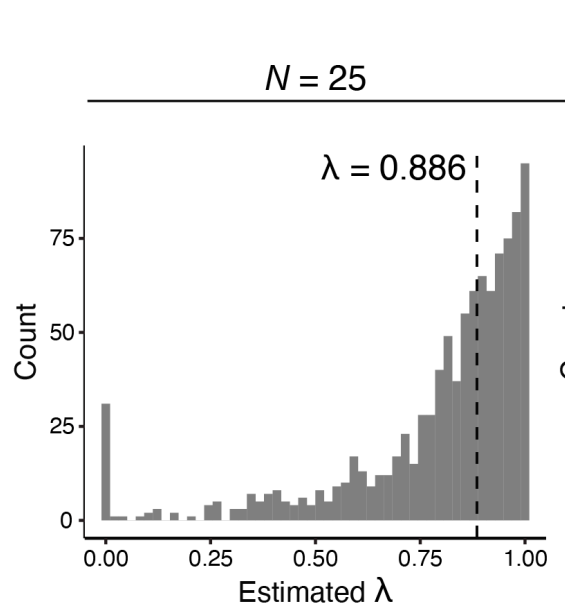

$\bar{\lambda}=0.795[0,1]$
Simulated Trees $N=50$

$N=100$
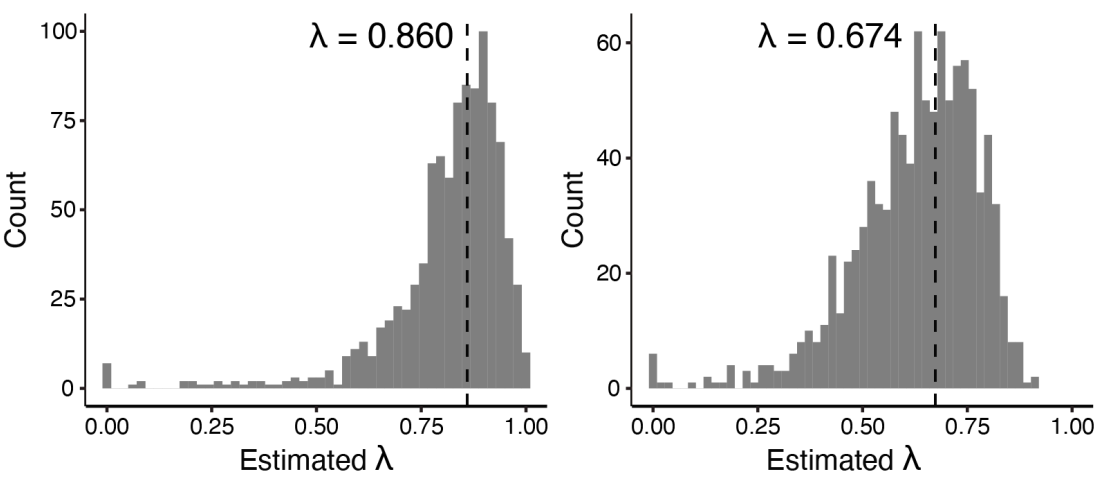

$\bar{\lambda}=0.812[0.376,0.977]$

$\bar{\lambda}=0.628[0.273,0.841]$

Supplemental Figure S5. Distribution of maximum likelihood estimates of $\lambda$ from 1,000 bootstrap replicates. The bootstrap analysis for our Wolbachia phylogram (Figure 2) is show to the left. To the right are simulated phylogenies with an increasing number of Wolbachia strains included $(N=25,50,100)$. For simulated trees, character evolution was simulated with our $\lambda$ estimate of 0.778 using the "sim.bdtree" and "sim.char" functions in the geiger R package (Harmon et al. 2008). For each graph, fitted $\lambda$ values for the original phylogeny are shown above with a vertical dashed line. Note that fitted $\lambda$ values for the simulated phylogenies differ slightly from $\lambda=0.778$, because "sim.char" uses a Brownian-motion model to simulate character evolution along the phylogeny. Below each graph, the mean estimate of $\lambda$ from the 1,000 replicates $(\bar{\lambda})$ is shown with associated $95 \%$ confidence intervals. The bootstrapping analyses generally show that small phylogenies $(N=8,25)$ have a large number of near-zero $\lambda$ values arising by random chance, which increases the uncertainty of parameter estimation. As the number of strains increases $(N=50,100)$, bootstrapped estimates of $\lambda$ cluster around the true $\lambda$ value fitted to the original phylogeny. 
559 Supplemental Table S1. Genotype IDs for different Wolbachia-infected host species used in 560 this study.

561

\begin{tabular}{lll}
\hline Species & Wolbachia & Genotype ID \\
\hline D. simulans & $w \mathrm{Ri}$ & Riv84 \\
D. simulans & $w \mathrm{Ha}$ & Car5 \\
D. melanogaster & $w \mathrm{MelCS}$ & Canton S Berkeley \\
D. melanogaster & $w \mathrm{Mel}$ & PC75 \\
D. mauritiana & $w \mathrm{Mau}$ & mauR31 \\
D. sechellia & $w \mathrm{Sh}$ & PmuseumbananaI \\
D. yakuba & $w \mathrm{Yak}$ & B13L5 \\
D. teissieri & $w \mathrm{Tei}$ & B13L11 \\
\hline
\end{tabular}


563 Supplemental Table S2. Mean temperature and standard error for each section of the custom564 built thermal gradient apparatus, across all 379 experimental replicates in this study.

565

\begin{tabular}{ccc}
\hline Section & Mean Temp. $\left({ }^{\circ} \mathbf{C}\right)$ & Std. Error \\
\hline 1 & 34.4 & 0.08 \\
2 & 30.5 & 0.08 \\
3 & 26.4 & 0.07 \\
4 & 22.7 & 0.06 \\
5 & 20.1 & 0.07 \\
6 & 18.2 & 0.06 \\
7 & 17.1 & 0.06 \\
\hline
\end{tabular}


bioRxiv preprint doi: https://doi.org/10.1101/2020.06.11.146977; this version posted June 12, 2020. The copyright holder for this preprint (which was not certified by peer review) is the author/funder, who has granted bioRxiv a license to display the preprint in perpetuity. It is made available under aCC-BY-NC-ND 4.0 International license.

567 Supplemental Table S3. $T_{p}$ data for the $w \mathrm{Ha}, w \mathrm{MelCS}, w \mathrm{Mel}$, and $w \mathrm{Mau}$ host genotypes 568 approximated a normal distribution. Results from LMMs for each $T_{p}$ dataset are shown below.

569 Statistically significant fixed effects at $P<0.05$ are marked in bold text with asterisks.

570

\begin{tabular}{|c|c|c|c|c|c|c|c|c|c|c|c|c|}
\hline \multirow[b]{2}{*}{$\begin{array}{l}\text { Explanatory } \\
\text { variable }\end{array}$} & \multicolumn{3}{|c|}{$w \mathbf{R i}$} & \multicolumn{3}{|c|}{$w \mathrm{Ha}$} & \multicolumn{3}{|c|}{$w$ MelCS } & \multicolumn{3}{|c|}{$w$ Mel } \\
\hline & coefficient & $x^{2}$ & $\begin{array}{c}P \\
\text { value }\end{array}$ & coefficient & $\chi^{2}$ & $\begin{array}{c}P \\
\text { value }\end{array}$ & coefficient & $\chi^{2}$ & $\begin{array}{c}P \\
\text { value }\end{array}$ & coefficient & $\chi^{2}$ & $\begin{array}{c}P \\
\text { value } \\
\end{array}$ \\
\hline Infection Status & 1.607 & 5.082 & $0.024 *$ & 1.576 & 5.201 & 0.023 * & -0.492 & 1.065 & 0.302 & -0.101 & 0.027 & 0.871 \\
\hline Sex & -1.360 & 3.544 & 0.060 & -1.640 & 5.438 & 0.020 * & -0.197 & 0.155 & 0.694 & -1.125 & 3.178 & 0.075 \\
\hline Age & -0.160 & 0.092 & 0.761 & -0.048 & 0.058 & 0.810 & -0.574 & 9.683 & $0.002 *$ & 0.316 & 2.165 & 0.141 \\
\hline Run Order & 0.026 & 0.013 & 0.909 & 0.167 & 0.533 & 0.465 & 0.314 & 3.613 & 0.057 & 0.103 & 0.264 & 0.608 \\
\hline Infection * Sex & -0.383 & 0.141 & 0.707 & -0.457 & 0.206 & 0.650 & 0.023 & 0.001 & 0.974 & 0.528 & 0.357 & 0.550 \\
\hline Sample Size & 1015 & & & 857 & & & 1727 & & & 1341 & & \\
\hline
\end{tabular}

\begin{tabular}{|c|c|c|c|c|c|c|c|c|c|c|c|c|}
\hline \multirow[b]{2}{*}{$\begin{array}{l}\text { Explanatory } \\
\text { variable }\end{array}$} & \multicolumn{3}{|c|}{$w$ Mau } & \multicolumn{3}{|c|}{$w \mathrm{Sh}$} & \multicolumn{3}{|c|}{$w$ Yak } & \multicolumn{3}{|c|}{$w$ Tei } \\
\hline & coefficient & $x^{2}$ & $\begin{array}{c}P \\
\text { value }\end{array}$ & coefficient & $\chi^{2}$ & $\begin{array}{c}P \\
\text { value }\end{array}$ & coefficient & $\chi^{2}$ & $\begin{array}{c}P \\
\text { value }\end{array}$ & coefficient & $\chi^{2}$ & $\begin{array}{c}P \\
\text { value } \\
\end{array}$ \\
\hline Infection Status & -1.871 & 5.086 & $0.024^{*}$ & 1.019 & 4.336 & $0.037^{*}$ & 0.035 & 0.003 & 0.958 & 0.734 & 5.573 & $0.018^{*}$ \\
\hline Sex & -1.088 & 2.127 & 0.145 & 0.261 & 0.314 & 0.575 & -0.248 & 0.143 & 0.705 & -0.469 & 2.300 & 0.129 \\
\hline Age & -0.349 & 1.509 & 0.219 & 0.072 & 0.109 & 0.742 & 0.608 & 2.814 & 0.093 & -0.257 & 2.305 & 0.129 \\
\hline Run Order & 0.456 & 3.065 & 0.080 & 0.253 & 2.673 & 0.102 & 0.223 & 1.073 & 0.300 & 0.022 & 0.049 & 0.824 \\
\hline Infection * Sex & 0.793 & 0.507 & 0.477 & -0.799 & 1.386 & 0.239 & 0.291 & 0.097 & 0.755 & 0.421 & 0.936 & 0.333 \\
\hline Sample Size & 818 & & & 1087 & & & 1056 & & & 2500 & & \\
\hline
\end{tabular}


bioRxiv preprint doi: https://doi.org/10.1101/2020.06.11.146977; this version posted June 12, 2020. The copyright holder for this preprint (which was not certified by peer review) is the author/funder, who has granted bioRxiv a license to display the preprint in perpetuity. It is made available under aCC-BY-NC-ND 4.0 International license.

572 Supplemental Table S4. Results and sample sizes from the GLMMs and LMMs including the 573 flies located in the coldest section of the thermal gradient apparatus (section 7). Statistically 574 significant fixed effects at $P<0.05$ are marked in bold text with asterisks.

GLMMs

\begin{tabular}{|c|c|c|c|c|c|c|c|c|c|c|c|c|}
\hline \multirow[b]{2}{*}{$\begin{array}{l}\text { Explanatory } \\
\text { variable }\end{array}$} & \multicolumn{3}{|c|}{$w \mathbf{R i}$} & \multicolumn{3}{|c|}{$w \mathrm{Ha}$} & \multicolumn{3}{|c|}{$w$ MelCS } & \multicolumn{3}{|c|}{$w$ Mel } \\
\hline & coefficient & $x^{2}$ & $\begin{array}{c}P \\
\text { value }\end{array}$ & coefficient & $x^{2}$ & $\begin{array}{c}P \\
\text { value }\end{array}$ & coefficient & $\chi^{2}$ & $\begin{array}{c}P \\
\text { value }\end{array}$ & coefficient & $\chi^{2}$ & $\begin{array}{c}P \\
\text { value }\end{array}$ \\
\hline Infection Status & 0.063 & 4.757 & $0.029 *$ & 0.066 & 6.513 & $0.011^{*}$ & -0.022 & 1.463 & 0.226 & 0.036 & 1.788 & 0.181 \\
\hline Sex & -0.066 & 5.115 & $0.024 *$ & -0.060 & 5.057 & $0.025^{*}$ & -0.007 & 0.156 & 0.693 & -0.045 & 2.743 & 0.098 \\
\hline Age & 0.001 & 0.002 & 0.968 & 0.005 & 0.394 & 0.530 & -0.024 & 12.093 & $0.001 *$ & 0.008 & 0.640 & 0.424 \\
\hline Run Order & 0.001 & 0.011 & 0.916 & 0.009 & 1.056 & 0.304 & 0.015 & 5.733 & $0.017 *$ & 0.020 & 5.374 & $0.020^{*}$ \\
\hline Infection * Sex & -0.028 & 0.454 & 0.501 & -0.020 & 0.281 & 0.596 & 0.003 & 0.016 & 0.900 & 0.012 & 0.099 & 0.753 \\
\hline Sample Size & 1534 & & & 1135 & & & 1770 & & & 1962 & & \\
\hline
\end{tabular}

\begin{tabular}{|c|c|c|c|c|c|c|c|c|c|c|c|c|}
\hline \multirow[b]{2}{*}{$\begin{array}{l}\text { Explanatory } \\
\text { variable }\end{array}$} & \multicolumn{3}{|c|}{$w$ Mau } & \multicolumn{3}{|c|}{$w \mathrm{Sh}$} & \multicolumn{3}{|c|}{$w$ Yak } & \multicolumn{3}{|c|}{$w$ Tei } \\
\hline & coefficient & $x^{2}$ & $\begin{array}{c}P \\
\text { value }\end{array}$ & coefficient & $\chi^{2}$ & $\begin{array}{c}P \\
\text { value }\end{array}$ & coefficient & $\chi^{2}$ & $\begin{array}{c}P \\
\text { value }\end{array}$ & coefficient & $\chi^{2}$ & $\begin{array}{c}P \\
\text { value }\end{array}$ \\
\hline Infection Status & -0.110 & 7.615 & $0.006 *$ & 0.047 & 5.835 & $0.016^{*}$ & 0.012 & 0.270 & 0.603 & 0.045 & 9.814 & $0.002 *$ \\
\hline Sex & -0.052 & 2.055 & 0.152 & 0.018 & 0.962 & 0.327 & -0.028 & 1.450 & 0.229 & -0.019 & 1.796 & 0.180 \\
\hline Age & -0.015 & 1.116 & 0.291 & 0.002 & 0.078 & 0.780 & 0.028 & 4.695 & $0.030^{*}$ & -0.013 & 3.039 & 0.081 \\
\hline Run Order & 0.022 & 3.045 & 0.081 & 0.018 & 8.319 & $0.004 *$ & 0.010 & 1.874 & 0.171 & 0.004 & 0.941 & 0.332 \\
\hline Infection * Sex & 0.063 & 1.383 & 0.240 & -0.026 & 0.920 & 0.337 & 0.022 & 0.450 & 0.502 & 0.018 & 0.808 & 0.369 \\
\hline Sample Size & 1009 & & & 1351 & & & 1232 & & & 2951 & & \\
\hline
\end{tabular}

LMMs

\begin{tabular}{|c|c|c|c|c|c|c|c|c|c|c|c|c|}
\hline & \multicolumn{3}{|c|}{$w \mathbf{R i}$} & \multicolumn{3}{|c|}{$w \mathrm{Ha}$} & \multicolumn{3}{|c|}{$w$ MelCS } & \multicolumn{3}{|c|}{$w$ Mel } \\
\hline $\begin{array}{l}\text { Explanatory } \\
\text { variable }\end{array}$ & coefficient & $\chi^{2}$ & $\begin{array}{c}P \\
\text { value }\end{array}$ & coefficient & $\chi^{2}$ & $\begin{array}{c}P \\
\text { value }\end{array}$ & coefficient & $\chi^{2}$ & $\begin{array}{c}P \\
\text { value }\end{array}$ & coefficient & $\chi^{2}$ & $\begin{array}{c}P P \\
\text { value }\end{array}$ \\
\hline Infection Status & 1.356 & 4.142 & $0.042 *$ & 1.548 & 5.477 & $0.019 *$ & -0.604 & 1.247 & 0.264 & 0.816 & 1.736 & 0.188 \\
\hline Sex & -1.344 & 4.077 & 0.043 * & -1.315 & 3.864 & $0.049 *$ & -0.189 & 0.109 & 0.741 & -0.942 & 2.307 & 0.129 \\
\hline Age & 0.052 & 0.011 & 0.915 & 0.112 & 0.341 & 0.559 & -0.671 & 10.257 & $0.001 *$ & 0.174 & 0.657 & 0.418 \\
\hline Run Order & 0.021 & 0.010 & 0.922 & 0.194 & 0.792 & 0.373 & 0.399 & 4.544 & $0.033 *$ & 0.435 & 4.733 & 0.030 * \\
\hline Infection * Sex & -0.655 & 0.483 & 0.487 & -0.541 & 0.318 & 0.573 & 0.094 & 0.014 & 0.907 & 0.213 & 0.059 & 0.809 \\
\hline Sample Size & 1534 & & & 1135 & & & 1770 & & & 1962 & & \\
\hline
\end{tabular}

\begin{tabular}{|c|c|c|c|c|c|c|c|c|c|c|c|c|}
\hline & \multicolumn{3}{|c|}{ wMau } & \multicolumn{3}{|c|}{$w$ Sh } & \multicolumn{3}{|c|}{$w$ Yak } & \multicolumn{3}{|c|}{$w$ Tei } \\
\hline $\begin{array}{l}\text { Explanatory } \\
\text { variable }\end{array}$ & coefficient & $x^{2}$ & $\begin{array}{c}P \\
\text { value }\end{array}$ & coefficient & $x^{2}$ & $\begin{array}{c}P \\
\text { value }\end{array}$ & coefficient & $\chi^{2}$ & $\begin{array}{c}P \\
\text { value }\end{array}$ & coefficient & $\chi^{2}$ & $\begin{array}{c}P \\
\text { value }\end{array}$ \\
\hline Infection Status & -2.232 & 5.971 & $0.015^{*}$ & 1.030 & 4.614 & $0.032 *$ & 0.286 & 0.218 & 0.641 & 0.907 & 7.640 & $0.006 *$ \\
\hline Sex & -1.048 & 1.611 & 0.204 & 0.392 & 0.732 & 0.392 & -0.634 & 1.112 & 0.292 & -0.502 & 2.416 & 0.120 \\
\hline Age & -0.288 & 0.836 & 0.360 & 0.055 & 0.067 & 0.796 & 0.639 & 3.658 & 0.056 & -0.280 & 2.475 & 0.116 \\
\hline Run Order & 0.441 & 2.326 & 0.127 & 0.397 & 6.853 & $0.009 *$ & 0.249 & 1.581 & 0.209 & 0.100 & 0.943 & 0.331 \\
\hline Infection * Sex & 1.292 & 1.102 & 0.294 & -0.624 & 0.875 & 0.350 & 0.486 & 0.319 & 0.572 & 0.515 & 1.257 & 0.262 \\
\hline Sample Size & 1009 & & & 1351 & & & 1232 & & & 2951 & & \\
\hline
\end{tabular}


578 Supplemental Table S5. The scaffold count, N50, and total assembly size of each Wolbachia 579 assembly.

580

\begin{tabular}{llccc}
\hline Genome & Host Genotype ID & $\begin{array}{c}\text { Scaffold } \\
\text { Count }\end{array}$ & N50 & $\begin{array}{c}\text { Total Assembly } \\
\text { Size }\end{array}$ \\
\hline$w \mathrm{Mel}$ & PC75 & 76 & 29,986 & $1,237,996$ \\
$w \mathrm{MelCS}$ & Canton S Berkeley & 89 & 25,105 & $1,233,787$ \\
$w \mathrm{Sh}$ & LD15 (Accession SRX3029362) & 83 & 25,919 & $1,294,885$ \\
\hline
\end{tabular}


582 Supplemental Table S6. qPCR primers used to measure relative Wolbachia density in temperature shift experiments.

\begin{tabular}{|c|c|c|c|c|c|c|c|c|}
\hline Species & Wolbachia & $\begin{array}{l}\text { Super } \\
\text { Group }\end{array}$ & $\begin{array}{l}\text { Insect } \\
\text { Locus }\end{array}$ & Forward Primer $\left(5^{\prime} \rightarrow 3^{\prime}\right)$ & Reverse Primer $\left(5^{\prime} \rightarrow 3^{\prime}\right)$ & $\begin{array}{l}\begin{array}{l}\text { Wolbachia } \\
\text { Locus }\end{array} \\
\end{array}$ & Forward Primer $\left(5^{\prime} \rightarrow 3^{\prime}\right)$ & Reverse Primer $\left(5^{\prime} \rightarrow 3^{\prime}\right)$ \\
\hline D. simulans & $w \mathrm{Ri}$ & A & $n A c R \alpha-34 E$ & CTATGGTCGTTGACAGACT & GTAGTACAGCTATTGTGGC & fst $Z$ & ATCCTTAACTGCGGCTCTTG & TTCATCACAGCAGGAATGGG \\
\hline D. simulans & $w \mathrm{Ha}$ & A & $n A c R \alpha-34 E$ & CTATGGTCGTTGACAGACT & GTAGTACAGCTATTGTGGC & $f_{s t} Z$ & ATCCTTAACTGCGGCTCTTG & TTCATCACAGCAGGAATGGG \\
\hline D. mauritiana & $w \mathrm{Mau}$ & B & $n A c R \alpha-34 E$ & CTATGGTCGTTGACAGACT & GTAGTACAGCTATTGTGGC & $f_{s t} Z$ & CAGAGAAGCAAGAGCGGTAG & TCTTCAAGTCCAAGCTCTGC \\
\hline D. sechellia & $w \mathrm{Sh}$ & A & Rpl32 & CCGCTTCAAGGGACAGTATC & CGATCTCCTTGCGCTTCTTG & $f_{s t} Z$ & ATCCTTAACTGCGGCTCTTG & TTCATCACAGCAGGAATGGG \\
\hline D. teissieri & $w \mathrm{Tei}$ & A & Rpl32 & TCGCTTCAAGGGACAGTATC & CGATCTCCTTGCGCTTCTTG & $f_{s t} Z$ & АTCCTTAACTGCGGCTCTTG & TTCATCACAGCAGGAATGGG \\
\hline
\end{tabular}


bioRxiv preprint doi: https://doi.org/10.1101/2020.06.11.146977; this version posted June 12, 2020. The copyright holder for this preprint (which was not certified by peer review) is the author/funder, who has granted bioRxiv a license to display the preprint in perpetuity. It is made available under aCC-BY-NC-ND 4.0 International license.

585 Supplemental Table S7. Results from $T_{p}$ assays. Sample sizes (n) and results are shown for 586 uninfected and infected flies of each genotype. Results for uninfected and infected flies are also 587 separated by sex.

\begin{tabular}{|c|c|c|c|c|c|c|}
\hline Species & Wolbachia & Infection & Status & $\mathrm{n}$ & Mean $T_{p}\left({ }^{\circ} \mathrm{C}\right)$ & Standard Error \\
\hline \multirow{6}{*}{ D. simulans } & \multirow{6}{*}{$w \mathrm{Ri}$} & Uninfected & & 504 & 23.1 & 0.18 \\
\hline & & & Female & 272 & 23.9 & 0.25 \\
\hline & & & Male & 232 & 22.2 & 0.24 \\
\hline & & Infected & & 511 & 21.7 & 0.14 \\
\hline & & & Female & 280 & 22.3 & 0.21 \\
\hline & & & Male & 231 & 21.1 & 0.17 \\
\hline \multirow{6}{*}{ D. simulans } & \multirow{6}{*}{$w \mathrm{Ha}$} & Uninfected & & 458 & 25.0 & 0.21 \\
\hline & & & Female & 239 & 25.9 & 0.27 \\
\hline & & & Male & 219 & 23.9 & 0.30 \\
\hline & & Infected & & 399 & 23.7 & 0.22 \\
\hline & & & Female & 218 & 24.5 & 0.30 \\
\hline & & & Male & 181 & 22.7 & 0.31 \\
\hline \multirow{6}{*}{ D. melanogaster } & \multirow{6}{*}{$w \mathrm{MelCS}$} & Uninfected & & 822 & 27.9 & 0.11 \\
\hline & & & Female & 376 & 28.0 & 0.17 \\
\hline & & & Male & 446 & 27.8 & 0.14 \\
\hline & & Infected & & 905 & 28.4 & 0.09 \\
\hline & & & Female & 452 & 28.2 & 0.14 \\
\hline & & & Male & 453 & 28.5 & 0.11 \\
\hline \multirow{6}{*}{ D. melanogaster } & \multirow{6}{*}{$w \mathrm{Mel}$} & Uninfected & & 702 & 24.3 & 0.18 \\
\hline & & & Female & 398 & 24.6 & 0.20 \\
\hline & & & Male & 304 & 24.0 & 0.30 \\
\hline & & Infected & & 639 & 24.1 & 0.18 \\
\hline & & & Female & 337 & 24.6 & 0.23 \\
\hline & & & Male & 302 & 23.6 & 0.28 \\
\hline \multirow{6}{*}{ D. mauritiana } & \multirow{6}{*}{$w \mathrm{Mau}$} & Uninfected & & 405 & 19.8 & 0.15 \\
\hline & & & Female & 177 & 20.2 & 0.22 \\
\hline & & & Male & 228 & 19.5 & 0.21 \\
\hline & & Infected & & 413 & 21.1 & 0.16 \\
\hline & & & Female & 200 & 21.5 & 0.22 \\
\hline & & & Male & 213 & 20.7 & 0.24 \\
\hline \multirow{6}{*}{ D. sechellia } & \multirow{6}{*}{$w \mathrm{Sh}$} & Uninfected & & 501 & 23.9 & 0.17 \\
\hline & & & Female & 233 & 24.1 & 0.27 \\
\hline & & & Male & 268 & 23.8 & 0.22 \\
\hline & & Infected & & 586 & 23.4 & 0.15 \\
\hline & & & Female & 279 & 23.3 & 0.24 \\
\hline & & & Male & 307 & 23.5 & 0.18 \\
\hline \multirow{6}{*}{ D. yakuba } & \multirow{6}{*}{$w$ Yak } & Uninfected & & 536 & 23.7 & 0.15 \\
\hline & & & Female & 277 & 23.6 & 0.19 \\
\hline & & & Male & 259 & 23.8 & 0.23 \\
\hline & & Infected & & 520 & 23.6 & 0.14 \\
\hline & & & Female & 273 & 23.7 & 0.19 \\
\hline & & & Male & 247 & 23.5 & 0.21 \\
\hline \multirow{6}{*}{ D. teissieri } & \multirow{6}{*}{$w$ Tei } & Uninfected & & 1337 & 23.7 & 0.10 \\
\hline & & & Female & 627 & 23.8 & 0.16 \\
\hline & & & Male & 710 & 23.6 & 0.13 \\
\hline & & Infected & & 1163 & 22.7 & 0.10 \\
\hline & & & Female & 552 & 22.9 & 0.14 \\
\hline & & & Male & 611 & 22.5 & 0.13 \\
\hline
\end{tabular}


589 Supplemental Table S8. Titer results from 24-hour temperature shift experiments.

590

\begin{tabular}{|c|c|c|c|c|c|c|c|}
\hline Species & Wolbachia & Temperature & Sex & $\begin{array}{l}\text { Biological } \\
\text { Replicates }\end{array}$ & $\begin{array}{c}\text { Median Relative } \\
\text { Wolbachia } \\
\text { Density }\left(2^{\Delta \mathrm{Ct}}\right)\end{array}$ & $\begin{array}{l}\text { Lower } \\
\text { Quartile }\end{array}$ & $\begin{array}{l}\text { Upper } \\
\text { Quartile }\end{array}$ \\
\hline \multirow{4}{*}{ D. simulans } & \multirow{4}{*}{$w \mathrm{Ri}$} & $18^{\circ} \mathrm{C}$ & $\mathrm{F}$ & 5 & 385.34 & 240.52 & 617.37 \\
\hline & & $18^{\circ} \mathrm{C}$ & M & 6 & 419.90 & 349.05 & 531.99 \\
\hline & & $25^{\circ} \mathrm{C}$ & $\mathrm{F}$ & 5 & 350.52 & 246.14 & 604.67 \\
\hline & & $25^{\circ} \mathrm{C}$ & M & 6 & 419.80 & 280.70 & 573.06 \\
\hline \multirow{4}{*}{ D. simulans } & \multirow{4}{*}{$w \mathrm{Ha}$} & $18^{\circ} \mathrm{C}$ & $\mathrm{F}$ & 6 & 105.56 & 83.96 & 136.76 \\
\hline & & $18^{\circ} \mathrm{C}$ & M & 6 & 112.02 & 104.86 & 124.60 \\
\hline & & $25^{\circ} \mathrm{C}$ & $\mathrm{F}$ & 6 & 125.36 & 107.02 & 156.51 \\
\hline & & $25^{\circ} \mathrm{C}$ & M & 6 & 107.15 & 102.15 & 123.32 \\
\hline \multirow{4}{*}{ D. mauritiana } & \multirow{4}{*}{$w \mathrm{Mau}$} & $18^{\circ} \mathrm{C}$ & $\mathrm{F}$ & 6 & 30.37 & 26.07 & 43.12 \\
\hline & & $18^{\circ} \mathrm{C}$ & M & 6 & 25.97 & 12.83 & 45.55 \\
\hline & & $25^{\circ} \mathrm{C}$ & $\mathrm{F}$ & 6 & 58.07 & 24.01 & 108.83 \\
\hline & & $25^{\circ} \mathrm{C}$ & M & 6 & 30.21 & 21.96 & 37.19 \\
\hline \multirow{4}{*}{ D. sechellia } & \multirow{4}{*}{$w \mathrm{Sh}$} & $18^{\circ} \mathrm{C}$ & $\mathrm{F}$ & 6 & 0.24 & 0.23 & 0.25 \\
\hline & & $18^{\circ} \mathrm{C}$ & M & 6 & 0.16 & 0.14 & 0.16 \\
\hline & & $25^{\circ} \mathrm{C}$ & $\mathrm{F}$ & 6 & 0.33 & 0.24 & 0.36 \\
\hline & & $25^{\circ} \mathrm{C}$ & M & 6 & 0.11 & 0.09 & 0.13 \\
\hline \multirow{4}{*}{ D. teissieri } & \multirow{4}{*}{$w$ Tei } & $18^{\circ} \mathrm{C}$ & $\mathrm{F}$ & 6 & 3.56 & 3.42 & 3.73 \\
\hline & & $18^{\circ} \mathrm{C}$ & M & 6 & 3.36 & 3.20 & 3.55 \\
\hline & & $25^{\circ} \mathrm{C}$ & $\mathrm{F}$ & 6 & 3.23 & 3.15 & 3.53 \\
\hline & & $25^{\circ} \mathrm{C}$ & $\mathrm{M}$ & 6 & 2.98 & 2.78 & 3.12 \\
\hline
\end{tabular}




\section{REFERENCES}

Adrion, J. R., M. W. Hahn, and B. S. Cooper. 2015. Revisiting classic clines in Drosophila melanogaster in the age of genomics. Trends in Genetics 31:434-444.

Albertson, R., C. Casper-Lindley, J. Cao, U. Tram, and W. Sullivan. 2009. Symmetric and asymmetric mitotic segregation patterns influence Wolbachia distribution in host somatic tissue. Journal of Cell Science 122:4570-4583.

Anderson, J. L., L. Albergotti, S. Proulx, C. Peden, R. B. Huey, and P. C. Phillips. 2007. Thermal preference of Caenorhabditis elegans: a null model and empirical tests. Journal of Experimental Biology 210:3107-3116.

Angilletta, M. J. 2009. Thermal adaptation: a theoretical and empirical synthesis. Oxford University Press.

Angilletta, M. J., T. D. Steury, and M. W. Sears. 2004. Temperature, growth rate, and body size in ectotherms: fitting pieces of a life-history puzzle. Integrative and Comparative Biology 44:498-509. Oxford University Press.

Arnold, P. A., S. C. Levin, A. L. Stevanovic, and K. N. Johnson. 2019. Drosophila melanogaster infected with Wolbachia strain wMelCS prefer cooler temperatures. Ecological Entomology 44:287-290.

Ballard, J., and R. Melvin. 2007. Tetracycline treatment influences mitochondrial metabolism and mtDNA density two generations after treatment in Drosophila. Insect Molecular Biology 16:799-802.

Ballard, J. W. O. 2000. Comparative genomics of mitochondrial DNA in members of the Drosophila melanogaster subgroup. Journal of Molecular Evolution 51:48-63.

Barton, N., and M. Turelli. 2011. Spatial waves of advance with bistable dynamics: cytoplasmic and genetic analogues of Allee effects. The American Naturalist 178:E48-E75.

Bates, D., M. Mächler, B. Bolker, and S. Walker. 2015. Fitting linear mixed-effects models using lme4. Journal of Statistical Software 67:1-48.

Baumann, P. 2005. Biology of bacteriocyte-associated endosymbionts of plant sap-sucking insects. Annual Review of Microbiology 59:155-189.

Bi, J., and Y.-F. Wang. 2019. The effect of the endosymbiont Wolbachia on the behavior of insect hosts. Insect Science, doi: 10.1111/1744-7917.12731.

Boettiger, C., G. Coop, and P. Ralph. 2012. Is your phylogeny informative? Measuring the power of comparative methods. Evolution 66:2240-2251.

Bordenstein, S. R., and S. R. Bordenstein. 2011. Temperature affects the tripartite interactions between bacteriophage WO, Wolbachia, and cytoplasmic incompatibility. PLoS One 6.

Brownlie, J. C., B. N. Cass, M. Riegler, J. J. Witsenburg, I. Iturbe-Ormaetxe, E. A. McGraw, and S. L. O’Neill. 2009. Evidence for metabolic provisioning by a common invertebrate endosymbiont, Wolbachia pipientis, during periods of nutritional stress. PLoS Pathogens 5:e1000368.

Brumin, M., S. Kontsedalov, and M. Ghanim. 2011. Rickettsia influences thermotolerance in the whitefly Bemisia tabaci B biotype. Insect Science 18:57-66. 
Caspari, E., and G. Watson. 1959. On the evolutionary importance of cytoplasmic sterility in mosquitoes. Evolution 13:568-570.

Charlesworth, J., L. A. Weinert, E. Araujo Jr, and J. J. Welch. 2019. Wolbachia, Cardinium and climate: an analysis of global data. Biology Letters 15:20190273.

Chown, S. L., and S. Nicolson. 2004. Insect physiological ecology: mechanisms and patterns. Oxford University Press.

Chrostek, E., M. S. P. Marialva, S. S. Esteves, L. A. Weinert, J. Martinez, F. M. Jiggins, and L. Teixeira. 2013. Wolbachia variants induce differential protection to viruses in Drosophila melanogaster: a phenotypic and phylogenomic analysis. PLoS Genetics 9:e1003896.

Clancy, D. J., and A. A. Hoffmann. 1998. Environmental effects on cytoplasmic incompatibility and bacterial load in Wolbachia-infected Drosophila simulans. Entomologia Experimentalis et Applicata 86:13-24.

Colomb, J., and B. Brembs. 2014. Sub-strains of Drosophila Canton-S differ markedly in their locomotor behavior. F1000Research 3 .

Condon, C., B. S. Cooper, S. Yeaman, and M. J. Angilletta Jr. 2014. Temporal variation favors the evolution of generalists in experimental populations of Drosophila melanogaster. Evolution 68:720-728.

Conner, W. R., M. L. Blaxter, G. Anfora, L. Ometto, O. Rota-Stabelli, and M. Turelli. 2017. Genome comparisons indicate recent transfer of $w$ Ri-like Wolbachia between sister species Drosophila suzukii and D. subpulchrella. Ecology and Evolution 7:9391-9404.

Cooper, B. S., P. S. Ginsberg, M. Turelli, and D. R. Matute. 2017. Wolbachia in the Drosophila yakuba complex: Pervasive frequency variation and weak cytoplasmic incompatibility, but no apparent effect on reproductive isolation. Genetics 205:333-351.

Cooper, B. S., L. A. Hammad, N. P. Fisher, J. A. Karty, and K. L. Montooth. 2012. In a variable thermal environment selection favors greater plasticity of cell membranes in Drosophila melanogaster. Evolution 66:1976-1984.

Cooper, B. S., D. Vanderpool, W. R. Conner, D. R. Matute, and M. Turelli. 2019. Wolbachia acquisition by Drosophila yakuba-clade hosts and transfer of incompatibility loci between distantly related Wolbachia. Genetics 212:1399-1419.

Correa, C. C., and J. W. O. Ballard. 2012. Wolbachia gonadal density in female and male Drosophila vary with laboratory adaptation and respond differently to physiological and environmental challenges. Journal of Invertebrate Pathology 111:197-204. Weston, M. Westoby, P. Wilf, and H. P. Linder. 2009. Phylogenetic biome conservatism on a global scale. Nature 458:754-756.

Curtis, V. A. 2014. Infection-avoidance behaviour in humans and other animals. Trends in Immunology 35:457-464.

Dankert, H., L. Wang, E. D. Hoopfer, D. J. Anderson, and P. Perona. 2009. Automated monitoring and analysis of social behavior in Drosophila. Nature Methods 6:297.

De Roode, J. C., and T. Lefèvre. 2012. Behavioral immunity in insects. Insects 3:789-820. 
Dean, M. D. 2006. A Wolbachia-associated fitness benefit depends on genetic background in Drosophila simulans. Proceedings of the Royal Society of London B: Biological Sciences 273:1415-1420.

Dierick, H. A. 2007. A method for quantifying aggression in male Drosophila melanogaster. Nature Protocols 2:2712.

Dillon, M. E., G. Wang, P. A. Garrity, and R. B. Huey. 2009. Thermal preference in Drosophila. Journal of Thermal Biology 34:109-119.

Dobson, S. L., K. Bourtzis, H. R. Braig, B. F. Jones, W. Zhou, F. Rousset, and S. L. O'Neill. 1999. Wolbachia infections are distributed throughout insect somatic and germ line tissues. Insect Biochemistry and Molecular Biology 29:153-160.

Douglas, A. E. 2009. The microbial dimension in insect nutritional ecology. Functional Ecology 23:38-47.

Dunbar, H. E., A. C. Wilson, N. R. Ferguson, and N. A. Moran. 2007. Aphid thermal tolerance is governed by a point mutation in bacterial symbionts. PLoS Biology 5 .

Ellegaard, K. M., L. Klasson, K. Näslund, K. Bourtzis, and S. G. Andersson. 2013. Comparative genomics of Wolbachia and the bacterial species concept. PLoS Genetics 9.

Fedorka, K. M., I. C. Kutch, L. Collins, and E. Musto. 2016. Cold temperature preference in bacterially infected Drosophila melanogaster improves survival but is remarkably suboptimal. Journal of Insect Physiology 93:36-41.

Feldhaar, H. 2011. Bacterial symbionts as mediators of ecologically important traits of insect hosts. Ecological Entomology 36:533-543.

Foo, I. J.-H., A. A. Hoffmann, and P. A. Ross. 2019. Cross-generational effects of heat stress on fitness and Wolbachia density in Aedes aegypti mosquitoes. Tropical Medicine and Infectious Disease 4:13.

Freckleton, R. P., P. H. Harvey, and M. Pagel. 2002. Phylogenetic analysis and comparative data: a test and review of evidence. The American Naturalist 160:712-726.

Fry, A., M. Palmer, and D. Rand. 2004. Variable fitness effects of Wolbachia infection in Drosophila melanogaster. Heredity 93:379.

Funkhouser-Jones, L. J., E. J. van Opstal, A. Sharma, and S. R. Bordenstein. 2018. The maternal effect gene Wds controls Wolbachia titer in Nasonia. Current Biology 28:1692-1702.

Garrity, P. A., M. B. Goodman, A. D. Samuel, and P. Sengupta. 2010. Running hot and cold: behavioral strategies, neural circuits, and the molecular machinery for thermotaxis in $C$. elegans and Drosophila. Genes \& Development 24:2365-2382.

Gerth, M., and C. Bleidorn. 2017. Comparative genomics provides a timeframe for Wolbachia evolution and exposes a recent biotin synthesis operon transfer. Nature Microbiology 2:16241.

Giordano, R., S. L. O'Neill, and H. M. Robertson. 1995. Wolbachia infections and the expression of cytoplasmic incompatibility in Drosophila sechellia and D. mauritiana. Genetics 140:1307-1317. 
Goda, T., J. R. Leslie, and F. N. Hamada. 2014. Design and analysis of temperature preference behavior and its circadian rhythm in Drosophila. Journal of Visualized Experiments e51097.

Goodacre, S. L., and O. Y. Martin. 2012. Modification of insect and arachnid behaviours by vertically transmitted endosymbionts: infections as drivers of behavioural change and evolutionary novelty. Insects 3:246-261.

Gruntenko, N. E., E. K. Karpova, N. V. Adonyeva, O. V. Andreenkova, E. V. Burdina, Y. Y. Ilinsky, R. A. Bykov, P. N. Menshanov, and I. Y. Rauschenbach. 2019. Drosophila female fertility and juvenile hormone metabolism depends on the type of Wolbachia infection. Journal of Experimental Biology 222:jeb195347.

Hague, M. T. J., H. Mavengere, D. R. Matute, and B. S. Cooper. 2020. Environmental and genetic contributions to imperfect $w$ Mel-like Wolbachia transmission and frequency variation. bioRxiv, doi: 10.1101/2020.06.09.142828.

Harmon, L. J., J. T. Weir, C. D. Brock, R. E. Glor, and W. Challenger. 2008. GEIGER: investigating evolutionary radiations. Bioinformatics 24:129-131.

Hart, B. L. 1988. Biological basis of the behavior of sick animals. Neuroscience \& Biobehavioral Reviews 12:123-137.

Hartl, D., and H. Jungen. 1979. Estimation of average fitness of populations of Drosophila melanogaster and the evolution of fitness in experimental populations. Evolution 371380.

Hedges, L. M., J. C. Brownlie, S. L. O’Neill, and K. N. Johnson. 2008. Wolbachia and virus protection in insects. Science 322:702-702.

Heil, M. 2016. Host manipulation by parasites: cases, patterns, and remaining doubts. Frontiers in Ecology and Evolution 4:80.

Hentschel, U., M. Steinert, and J. Hacker. 2000. Common molecular mechanisms of symbiosis and pathogenesis. Trends in Microbiology 8:226-231.

Hoekstra, L. A., M. A. Siddiq, and K. L. Montooth. 2013. Pleiotropic effects of a mitochondrialnuclear incompatibility depend upon the accelerating effect of temperature in Drosophila. Genetics 195:1129-1139.

Hoffmann, A. 2010. Physiological climatic limits in Drosophila: patterns and implications. Journal of Experimental Biology 213:870-880.

Hoffmann, A. A., A. Anderson, and R. Hallas. 2002. Opposing clines for high and low temperature resistance in Drosophila melanogaster. Ecology Letters 5:614-618.

Hoffmann, A. A., and C. M. Sgro. 2011. Climate change and evolutionary adaptation. Nature 470:479-485.

Hoffmann, A. A., and M. Turelli. 1997. Cytoplasmic incompatibility in insects. Influential Passenger: Inherited Microorganisms and Arthropod Reproduction 42-80.

Hoffmann, A. A., M. Turelli, and L. G. Harshman. 1990. Factors affecting the distribution of cytoplasmic incompatibility in Drosophila simulans. Genetics 126:933-948. 
Hoffmann, A. A., M. Turelli, and G. M. Simmons. 1986. Unidirectional incompatibility between populations of Drosophila simulans. Evolution 40:692-701.

752

753

754

755

756

757

758

759

760

761

762

763

764

765

766

767

768

769

770

771

772

773

774

775

776

777

778

779

780

781

782

783

784

785

786

787

788

789

790

Hoffmann, A. A., and A. R. Weeks. 2007. Climatic selection on genes and traits after a 100 yearold invasion: a critical look at the temperate-tropical clines in Drosophila melanogaster from eastern Australia. Genetica 129:133.

Höhna, S., M. J. Landis, T. A. Heath, B. Boussau, N. Lartillot, B. R. Moore, J. P. Huelsenbeck, and F. Ronquist. 2016. RevBayes: Bayesian phylogenetic inference using graphical models and an interactive model-specification language. Systematic Biology 65:726-736.

Hosokawa, T., and T. Fukatsu. 2020. Relevance of microbial symbiosis to insect behavior. Current Opinion in Insect Science.

Huey, R. B., and D. Berrigan. 2001. Temperature, demography, and ectotherm fitness. The American Naturalist 158:204-210.

Huey, R. B., M. R. Kearney, A. Krockenberger, J. A. Holtum, M. Jess, and S. E. Williams. 2012. Predicting organismal vulnerability to climate warming: roles of behaviour, physiology and adaptation. Philosophical Transactions of the Royal Society B: Biological Sciences 367:1665-1679.

Jackman, S. D., B. P. Vandervalk, H. Mohamadi, J. Chu, S. Yeo, S. A. Hammond, G. Jahesh, H. Khan, L. Coombe, R. L. Warren, and others. 2017. ABySS 2.0: resource-efficient assembly of large genomes using a Bloom filter. Genome Research 27:768-777.

James, A., M. Dean, M. McMahon, and J. Ballard. 2002. Dynamics of double and single Wolbachia infections in Drosophila simulans from New Caledonia. Heredity 88:182189.

Joshi, N., J. Fass, and others. 2011. Sickle: A sliding-window, adaptive, quality-based trimming tool for FastQ files.

Kellermann, V., V. Loeschcke, A. A. Hoffmann, T. N. Kristensen, C. Fløjgaard, J. R. David, J.C. Svenning, and J. Overgaard. 2012. Phylogenetic contstraints in key functiontal traits behind species' climate niches: patterns of desiccation and cold resistance across 95 Drosophila species. Evolution 66:3377-3389.

Kellermann, V., B. van Heerwaarden, C. M. Sgrò, and A. A. Hoffmann. 2009. Fundamental evolutionary limits in ecological traits drive Drosophila species distributions. Science 325:1244-1246.

Klasson, L., J. Westberg, P. Sapountzis, K. Näslund, Y. Lutnaes, A. C. Darby, Z. Veneti, L. Chen, H. R. Braig, R. Garrett, and others. 2009. The mosaic genome structure of the Wolbachia $w$ Ri strain infecting Drosophila simulans. Proceedings of the National Academy of Sciences 106:5725-5730.

Kriesner, P., W. R. Conner, A. R. Weeks, M. Turelli, and A. A. Hoffmann. 2016. Persistence of a Wolbachia infection frequency cline in Drosophila melanogaster and the possible role of reproductive dormancy. Evolution 70:979-997.

Kriesner, P., and A. A. Hoffmann. 2018. Rapid spread of a Wolbachia infection that does not affect host reproduction in Drosophila simulans cage populations. Evolution 72:14751487. 
Lefevre, T., and F. Thomas. 2008. Behind the scene, something else is pulling the strings: emphasizing parasitic manipulation in vector-borne diseases. Infection, Genetics and Evolution 8:504-519.

López-Madrigal, S., and E. H. Duarte. 2019. Titer regulation in arthropod-Wolbachia symbioses. FEMS Microbiology Letters 366:fnz232.

Martin, T. L., and R. B. Huey. 2008. Why “suboptimal” is optimal: Jensen's inequality and ectotherm thermal preferences. The American Naturalist 171:E102-E118.

Martinez, J., B. Longdon, S. Bauer, Y.-S. Chan, W. J. Miller, K. Bourtzis, L. Teixeira, and F. M. Jiggins. 2014. Symbionts commonly provide broad spectrum resistance to viruses in insects: A comparative analysis of Wolbachia strains. PLoS Pathogens 10:e1004369.

Matute, D. R., C. J. Novak, and J. A. Coyne. 2009. Temperature-based extrinsic reproductive isolation in two species of Drosophila. Evolution 63:595-612.

Meany, M. K., W. R. Conner, S. V. Richter, J. A. Bailey, M. Turelli, and B. S. Cooper. 2019. Loss of cytoplasmic incompatibility and minimal fecundity effects explain relatively low Wolbachia frequencies in Drosophila mauritiana. Evolution 73:1278-1295.

Mercot, H., B. Llorente, M. Jacques, A. Atlan, and C. Montchamp-Moreau. 1995. Variability within the Seychelles cytoplasmic incompatibility system in Drosophila simulans. Genetics 141:1015-1023.

Moghadam, N. N., P. M. Thorshauge, T. N. Kristensen, N. de Jonge, S. Bahrndorff, H. Kjeldal, and J. L. Nielsen. 2018. Strong responses of Drosophila melanogaster microbiota to developmental temperature. Fly 12:1-12.

Moran, N. A., J. P. McCutcheon, and A. Nakabachi. 2008. Genomics and evolution of heritable bacterial symbionts. Annual Review of Genetics 42:165-190.

Mouton, L., H. Henri, M. Bouletreau, and F. Vavre. 2006. Effect of temperature on Wolbachia density and impact on cytoplasmic incompatibility. Parasitology 132:49-56.

Mouton, L., H. Henri, D. Charif, M. Boulétreau, and F. Vavre. 2007. Interaction between host genotype and environmental conditions affects bacterial density in Wolbachia symbiosis. Biology Letters 3:210-213.

Mueller, U. G., A. S. Mikheyev, E. Hong, R. Sen, D. L. Warren, S. E. Solomon, H. D. Ishak, M. Cooper, J. L. Miller, K. A. Shaffer, and others. 2011. Evolution of cold-tolerant fungal symbionts permits winter fungiculture by leafcutter ants at the northern frontier of a tropical ant-fungus symbiosis. Proceedings of the National Academy of Sciences 108:4053-4056.

Newton, I. L., and D. W. Rice. 2020. The Jekyll and Hyde symbiont: could Wolbachia be a nutritional mutualist? Journal of Bacteriology 202.

Nikoh, N., T. Hosokawa, M. Moriyama, K. Oshima, M. Hattori, and T. Fukatsu. 2014. Evolutionary origin of insect-Wolbachia nutritional mutualism. Proceedings of the National Academy of Sciences 111:10257-10262. 
Nunes, M. D. S., V. Nolte, and C. Schlötterer. 2008. Nonrandom Wolbachia infection status of Drosophila melanogaster strains with different mtDNA haplotypes. Molecular Biology and Evolution 25:2493-2498.

Olsen, K., K. T. Reynolds, and A. A. Hoffmann. 2001. A field cage test of the effects of the endosymbiont Wolbachia on Drosophila melanogaster. Heredity 86:731-737.

O’Neill, S. L., R. Giordano, A. M. Colbert, T. L. Karr, and H. M. Robertson. 1992. 16S rRNA phylogenetic analysis of the bacterial endosymbionts associated with cytoplasmic incompatibility in insects. Proceedings of the National Academy of Sciences 89:26992702.

O’Neill, S. L., and T. L. Karr. 1990. Bidirectional incompatibility between conspecific populations of Drosophila simulans. Nature 348:178-180.

Osborne, S. E., Y. S. Leong, S. L. O’Neill, and K. N. Johnson. 2009. Variation in antiviral protection mediated by different Wolbachia strains in Drosophila simulans. PLoS Pathogens 5:e1000656.

Pagel, M. 1999. Inferring the historical patterns of biological evolution. Nature 401:877-884.

Pfaffl, M. W. 2001. A new mathematical model for relative quantification in real-time RT-PCR. Nucleic Acids Research 29:e45-e45.

Pietri, J. E., H. DeBruhl, and W. Sullivan. 2016. The rich somatic life of Wolbachia. MicrobiologyOpen 5:923-936.

Poulin, R. 2010. Parasite manipulation of host behavior: an update and frequently asked questions. Pp. 151-186 in Advances in the Study of Behavior. Elsevier.

Quintero, I., and J. J. Wiens. 2013. Rates of projected climate change dramatically exceed past rates of climatic niche evolution among vertebrate species. Ecology Letters 16:10951103.

R Core Team. 2018. R: A language and environment for statistical computing. R Foundation for Statistical Computing, Vienna, Austria.

Rajpurohit, S., and P. S. Schmidt. 2016. Measuring thermal behavior in smaller insects: A case study in Drosophila melanogaster demonstrates effects of sex, geographic origin, and rearing temperature on adult behavior. Fly 10:149-161.

Raychoudhury, R., L. Baldo, D. C. Oliveira, and J. H. Werren. 2009. Modes of acquisition of Wolbachia: Horizontal transfer, hybrid introgression, and codivergence in the Nasonia species complex. Evolution 63:165-183.

Revell, L. J. 2012. phytools: an R package for phylogenetic comparative biology (and other things). Methods in Ecology and Evolution 3:217-223.

Reynolds, K. T., and A. A. Hoffmann. 2002. Male age, host effects and the weak expression or non-expression of cytoplasmic incompatibility in Drosophila strains infected by maternally transmitted Wolbachia. Genetics Research 80:79-87.

Richardson, M. F., L. A. Weinert, J. J. Welch, R. S. Linheiro, M. M. Magwire, F. M. Jiggins, and C. M. Bergman. 2012. Population genomics of the Wolbachia endosymbiont in Drosophila melanogaster. PLoS Genetics 8:e1003129. 
Riegler, M., M. Sidhu, W. J. Miller, and S. L. O’Neill. 2005. Evidence for a global Wolbachia replacement in Drosophila melanogaster. Current Biology 15:1428-1433.

Ross, P. A., S. A. Ritchie, J. K. Axford, and A. A. Hoffmann. 2019a. Loss of cytoplasmic incompatibility in Wolbachia-infected Aedes aegypti under field conditions. PLoS Neglected Tropical Diseases 13:e0007357.

Ross, P. A., M. Turelli, and A. A. Hoffmann. 2019b. Evolutionary ecology of Wolbachia releases for disease control. Annual Review of Genetics 53.

Ross, P. A., I. Wiwatanaratanabutr, J. K. Axford, V. L. White, N. M. Endersby-Harshman, and A. A. Hoffmann. 2017. Wolbachia infections in Aedes aegypti differ markedly in their response to cyclical heat stress. PLoS Pathogens 13:e1006006.

Rousset, F., and M. Solignac. 1995. Evolution of single and double Wolbachia symbioses during speciation in the Drosophila simulans complex. Proceedings of the National Academy of Sciences 92:6389-6393.

Russell, J. A., and N. A. Moran. 2006. Costs and benefits of symbiont infection in aphids: variation among symbionts and across temperatures. Proceedings of the Royal Society B: Biological Sciences 273:603-610.

Schrider, D. R., J. Ayroles, D. R. Matute, and A. D. Kern. 2018. Supervised machine learning reveals introgressed loci in the genomes of Drosophila simulans and D. sechellia. PLoS Genetics 14:1-29.

Seemann, T. 2014. Prokka: rapid prokaryotic genome annotation. Bioinformatics 30:2068-2069.

Serbus, L. R., and W. Sullivan. 2007. A cellular basis for Wolbachia recruitment to the host germline. PLoS Pathogens 3:e190.

Shi, M., V. L. White, T. Schlub, J.-S. Eden, A. A. Hoffmann, and E. C. Holmes. 2018. No detectable effect of Wolbachia w Mel on the prevalence and abundance of the RNA virome of Drosophila melanogaster. Proceedings of the Royal Society B: Biological Sciences 285:20181165.

Siddiqui, W., and C. Barlow. 1972. Population growth of Drosophila melanogaster (Diptera: Drosophilidae) at constant and alternating temperatures. Annals of the Entomological Society of America 65:993-1001.

Stern, C. 1943. Genic action as studied by means of the effects of different doses and combinations of alleles. Genetics 28:441.

Stern, C., and E. W. Schaeffer. 1943. On primary attributes of alleles in Drosophila melanogaster. Proceedings of the National Academy of Sciences 29:351.

Stouthamer, R., and R. Luck. 1993. Influence of microbe-associated parthenogenesis on the fecundity of Trichogramma deion and T. pretiosum. Entomologia Experimentalis et Applicata 67:183-192.

Sumi, T., K. Miura, and T. Miyatake. 2017. Wolbachia density changes seasonally amongst populations of the pale grass blue butterfly, Zizeeria maha (Lepidoptera: Lycaenidae). PLoS One 12. 
908

909

910

911

912

913

914

915

916

917

918

919

920

921

922

923

924

925

926

927

928

929

930

931

932

933

934

935

936

937

938

939

940

941

942

943

944

945

946

947

Teixeira, L., Á. Ferreira, and M. Ashburner. 2008. The bacterial symbiont Wolbachia induces resistance to RNA viral infections in Drosophila melanogaster. PLoS Biology 6:e1000002.

Tittensor, D. P., C. Mora, W. Jetz, H. K. Lotze, D. Ricard, E. V. Berghe, and B. Worm. 2010. Global patterns and predictors of marine biodiversity across taxa. Nature 466:1098-1101.

Truitt, A. M., M. Kapun, R. Kaur, and W. J. Miller. 2019. Wolbachia modifies thermal preference in Drosophila melanogaster. Environmental Microbiology 21:3259-3268.

Turelli, M., B. S. Cooper, K. M. Richardson, P. S. Ginsberg, B. Peckenpaugh, C. X. Antelope, K. J. Kim, M. R. May, A. Abrieux, D. A. Wilson, M. J. Bronski, B. R. Moore, J.-J. Gao, M. B. Eisen, J. C. Chiu, W. R. Conner, and A. A. Hoffmann. 2018. Rapid global spread of wRi-like Wolbachia across multiple Drosophila. Current Biology 28:963-971.e8.

Turelli, M., and A. A. Hoffmann. 1995. Cytoplasmic incompatibility in Drosophila simulans: dynamics and parameter estimates from natural populations. Genetics 140:1319-1338.

Ulrich, J. N., J. C. Beier, G. J. Devine, and L. E. Hugo. 2016. Heat sensitivity of wMel Wolbachia during Aedes aegypti development. PLoS Neglected Tropical Diseases 10:e004873.

Umina, P. A., A. R. Weeks, M. R. Kearney, S. W. McKechnie, and A. A. Hoffmann. 2005. A rapid shift in a classic clinal pattern in Drosophila reflecting climate change. Science 308:691-693.

Vale, P. F., A. Siva-Jothy, A. Morrill, and M. R. Forbes. 2018. The influence of parasites. Pp. 273-291 in Insect behavior: from mechanisms to ecological and evolutionary consequences. Oxford University Press Oxford.

van Houte, S., V. I. Ros, and M. M. van Oers. 2013. Walking with insects: molecular mechanisms behind parasitic manipulation of host behaviour. Molecular Ecology 22:3458-3475.

Versace, E., V. Nolte, R. V. Pandey, R. Tobler, and C. Schlötterer. 2014. Experimental evolution reveals habitat-specific fitness dynamics among Wolbachia clades in Drosophila melanogaster. Molecular Ecology 23:802-814.

Weeks, A. R., M. Turelli, W. R. Harcombe, K. T. Reynolds, and A. A. Hoffmann. 2007. From parasite to mutualist: Rapid evolution of Wolbachia in natural populations of Drosophila. PLoS Biology 5:e114.

Weinersmith, K. L. 2019. What's gotten into you?: A review of recent research on parasitoid manipulation of host behavior. Current Opinion in Insect Science.

Weinert, L. A., E. V. Araujo-Jnr, M. Z. Ahmed, and J. J. Welch. 2015. The incidence of bacterial endosymbionts in terrestrial arthropods. Proceedings of the Royal Society B: Biological Sciences 282:20150249.

Wernegreen, J. J. 2012. Mutualism meltdown in insects: bacteria constrain thermal adaptation. Current Opinion in Microbiology 15:255-262.

Werren, J. H., L. Baldo, and M. E. Clark. 2008. Wolbachia: master manipulators of invertebrate biology. Nature Reviews Microbiology 6:741-751. 
948 Zhang, B., S. P. Leonard, Y. Li, and N. A. Moran. 2019. Obligate bacterial endosymbionts limit 949 thermal tolerance of insect host species. Proceedings of the National Academy of $950 \quad$ Sciences 116:24712-24718.

951 Zug, R., and P. Hammerstein. 2012. Still a host of hosts for Wolbachia: Analysis of recent data $952 \quad$ suggests that $40 \%$ of terrestrial arthropod species are infected. PLoS One 7:e38544. 